\title{
MALE AND FEMALE ROLES IN THE LYRICS OF THREE GENRES OF CONTEMPORARY MUSIC
}

\author{
THESIS
}

\begin{abstract}
Presented to the Graduate Council of the North Texas State University in Partial Fulfiliment of the Requirements
\end{abstract}

For the Degree of

MASTER OF SCIENCE

By

Patricia T. Freudiger, B. S. Denton, Texas

December, 1974 
Freudiger, Patricia T., Male and Female Roles in the Lyrics of Three Genres of Contemporary Music. Master of Science (Sociology), December, 1974, 147 pp., 10 tables, bibliography, 63 titles.

A sample of the top fifty songs of 1973 in Soul, CountryWestern, and Easy Listening music is content-analyzed to determine dominant theme and type of love relationship presented.

Most of the songs are about women and are sung by men. Hence, male artists continue to dominate the record industry. Criteria for evaluating direction of presentation are applied to lyrics to determine how men present women and women present men.

Songs with the heterosexual theme are analyzed to determine conformity to six male and six female stereotypical traits. Males conform to the male stereotype in larger percentages than females conform to the female stereotype. Differences in female role expectations vary among the three genres. 
TABLE OF CONTENTS

Page

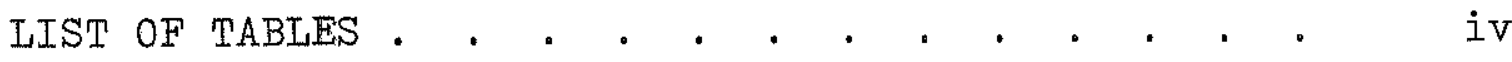

Chapter

I. POPULAR MUSIC AND SEX ROLES IN UNITED STATES

SOCIETY . . . . . . . . .

Popular Music

Sex Role Stereotyping

A Review of Lyric Analyses

Male-Female Communication Patterns

II. METHODOLOGY AND RESEARCH DESIGN . . . . 44

Content Analysis

Research Design

III. ANALYSIS OF PERFORMERS, THENES, AND LOVE

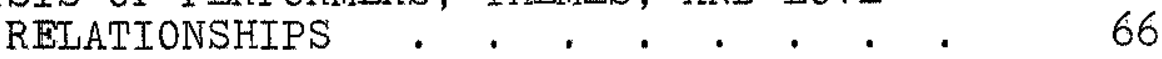

Performers

Themes

IV. ANALYSES OF ADDRESS, PRESENTATION, AND SEX

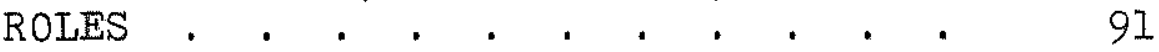

Analysis of Address

Analysis of Direction of Presentation Analysis of Sex Roles

V. CONCLUSION . . . . . . . . . . . 120

APPENDIX A . . . . . . . . . . . . . 134

APPENDIX B . . . . . . . . . . . . . 138

APPENDIX C . . . . . . . . . . . . . . 141

BIBLIOGRAPHY . . . . . . . . . . . . 142 


\section{LIST OF TABLES}

Table

Page

I. Type of Performer by Type of Music . . . . 67

II. Analysis of Themes by Type of Music . . . 70

III. Analysis of Love Relationship by Gender and Type of Music . . . . . . . 71

IV. Analysis of Address by Type of Music . . . 92

V. Analysis of the Direction of Presentation by Gender and Type of Music . . . . . 94

VI. Analysis of Conformity to Sex Role Stereotype Traits in Females... . . . . . 101

VII. A Comparison of Female Stereotypes in Three Genres of Music . . . . . . 103

VIII. Analysis of Conformity to Sex Role Stereotype Traits in Males . . . . . . . . 109

IX. A Comparison of Male Stereotypes in Three
Genres of Music . . . . . . . 110

X. A Comparison of Conformity to Stereotypical Traits by Sex . . . . . . . . 118 


\section{CHAPTER I}

\section{POPUEAR MUSIC AND SEX ROLES IN \\ UNITED STATES SOCIETY}

\section{Popular Music}

The study of socializing processes in American society has focused on the traditional institutions of family, religion, and education. of more recent importance is the role of the mass media in socializing Americans. Many studies have concentrated on describing the content of television, literature, and films. Iittle has been written about the role of popular music as a socializing agent in American society. Its effect on the socialization process is at present unknown. Of special interest is the impact popular music has on the process of sex role socialization. This paper will attempt to assess the role of popular music lyrics in our society and to describe their content and possible impact on the sex role socialization process.

Popular songs are the ubiquitous whispers of United States culture. Their messages drum an almost subliminal litany into the collective consciousness of the American mass public. Popular music is disseminated to an ever-available audience by means of electronic technology which would stagger the imagination of musicians of earlier musical eras. 


\section{Dissemination of Popular Music}

Media critic Marshall McLuhan says that the uniting of radio with the phonograph produces a "special pattern" which is superior to either medium alone (33, p. 268). This wedding of two important media has created a different world for both in which recorded music is disseminated by means of radio's portability to an ever expanding public market. One cannot mention radio without assessing the impact of the transistor on that medium. McLuhan comments on the trend which has personalized radio programming. The multiplicity of receiving sets in bedrooms, bathrooms, kitchens, cars, and now in pockets enables the teenager to withdraw from group activities such as television viewing to "his private radio" (33, pp. 267-268). In discussing the impact of the transistor, a Time essay notes that "in terms of human lives, one of the most revolutionary inventions in this age of communication is the transistor radio." Those little boxes massaging the minds of adolescents are asserted by Time to be an important element in revolutionizing communication (46, p. 35).

To what are the owners of these transistors, and other radios, listening? According to research, teenaged listeners to "Top Forty" or popular music stations do not constitute a single audience. Instead, teenaged radio listeners break down into separate social groupings, who listen for their particular song style. In the sample of teenaged radio 
listeners in Grand Rapids and Detroit studied by Robinson and Hirsch, this selective perception on the part of listeners was interpreted as being a function of their social class and ethnic identity. "Black students in Grand Rapids were almost unanimously aware of the latest rhythm and blues records played over the local Top Forty station, but claimed to have 'not heard' songs by a number of white singers which were aired by the same stations." Hirsch and Robinson were concerned with how their sample of seven hundred seventy subjects interpreted protest lyrics. They concluded that liking a particular song and understanding the meaning of its lyrics are two distinct phenomena (43, pp. 228-230).

What about the other half of the radio-phonograph union? Heinz otto Luthe describes the record industry as the poor relation of social scientists. Luthe believes the record differs from other media in several ways. One listens to the record in spatial independence, and perhaps intensely over a relatively short period of time. The record may be repeated over this period of time to an extent that is unknown. Further, recorded music may be listened to in solitude, as evidenced by the popularity of earphones for use with stereo units. Records are sold through shops, stores, and record clubs, and the industry is extremely dependent on radio to popularize records. Record listeners, Luthe suggests, are seeking escapism and fleeing social reality. The factors associated with record listening are unclear, but the record 
may exert an influence which is formidable in scope (32). We might add to this McLuhan's observation that stereo is to recorded music what cubism is to painting, the acceptance of "multiple facets and planes in a single experience" (33, p. 247$)$.

\section{Functions of Listening to Music}

Sociologist David Riesman suggests that Lasswell's formula "who says what to whom with what effect" varies with the audience. One role of popular music in socializing the young may be to create a picture of adolescence in America as a happy-go-lucky time. Riesman also asserts that in addition to this youth stereotype, the mass media also furnish stereotypes for other groups such as blacks, women, and the lower classes (42, pp. 409-410). The lyrics of popular music tell people, almost without their awareness, how to feel about their problems in much the same way as day time serials. A minority group may use popular music to polarize itself from the majority group, and thereby from popular culture generally.

S. I. Hayakawa suggests that popular lyrics have two functions with regard to the emotional life: they introduce us vicariously to emotions and situations with which we are not yet acquainted and they enable us to organize the experiences we have already had and come to terms with them. Hayakawa questions whether popular songs, listened to, often 
memorized, and sung in the course of adolescent and youthful courtship make the attaining of emotional maturity more difficult than it need be (2I, p. 400).

Evidently adolescents do listen to popular music. In 1958, James S. Coleman surveyed adolescent culture and found that teenagers reported their favorite leisure activity as "listening to records or radio" 31.7 per cent of the time if they were females and 11 per cent of the time if they were males. Approximately 50 per cent of both sexes reported a preference for rock music. As Coleman states, "For adolescent girls, popular songs are consistent with and reinforce the 'romantic' role which they are expected to play, while songs have no such function for boys" (14, p. 127). It would seem, however, that boys would be affected, at least indirectly, by the girls perception of their own, and the boys', roles.

Less is known about the impact of popular music on young adults, particularly those not in the college population. One study of the urban poor, however, found that 59 per cent of a sample of 280 subjects listened to a phonograph the day before. Well over 60 per cent of the same group reported also listening to the radio. Teenaged members of the sample reported two hours of radio listening and over one hour of record playing the previous day. When the low income group was dichotomized between black and white, it was found that black children listened to a record player more often than did white. Black respondents reported a 30 per cent greater 
use of the record player than did white respondents. No differences were found in radio listening time between black and white subjects (20).

There are 4,324 AM radio stations and 2,258 FM radio stations broadcasting in the United States (2). Record sales are estimated by some sources to exceed two billion dollars per year (47, p. 51). These estimates do not include juke box plays, live performances, and other modes of dissemination. Popular music is big business in the United States and evidently much in demand by the public. One might ask, then, what is the nature of that which is communicated? Billboard magazine and the music industry in general recognize three large categories of popular music: Easy Listening (which includes rock, folk, and romantic music), CountryWestern, and Soul (also called rhythm and blues). Each genre has its own listeners, performers, and presumably its own values which appeal to its devotees. These three genres have not always been so easily categorized, however. Their areas of influence are a function of United States subcultures which differ widely.

Lyrics in American Culture

Historian H. F. Mooney asserts that the changing lyrics of popular songs have reflected basic changes in the social structure of the United States. While the lyrics of the twenties and thirties reflected artistic and sexual rebellion, 
it was a rebellion of the white middle class. An urbane, affluent, and post-adolescent middle-class dominated music consumption in this era. Citing lyric references to "candle light and wine/ Castles on the Rhine" and the Parthenon as examples, Mooney reflects that these were aimed at an audience that was mature and educated. Blacks, who had their own music and style, were not influential in this period because they were "little short of outcasts, too poor and too segregated from the mainstream of life to maximally influence taste (38, p. 256). Composers and lyricists of this period were frequently Jewish middle-class people who thoroughly respected and reflected the almost Victorian gentility of this period. Mooney concedes that black and Jew had a common bitterness, alienation, and sadness, but those whose music was accepted had passed through a refining period of cultural acceptance. How this trend, which continued into the forties, became radically changed in the fifties and sixties, is explained by Mooney. The black movement, the youth culture, and a more affluent lower class which could afford to indulge in record purchases, all functioned to change musical taste. Further, there was a concomitant decline in the Victorian ethic. The attitudes of these groups and the function of a new religious ideology all contributed to a new vision of the love-sex concept in lyrics. While Mooney does not speak of images of either sex in particular, he asserts that boys in the lyrics of the sixties did not worship girls in "1942 style," nor did 
girls promote this sort of veneration (38, p. 253). Those white artists who were popular conformed to Mailer's image of the "white Negro" whose heat, volume, drive and "guttiness" appealed to the youth culture of the sixties. The intellectual and plebian revolt against the middle class in the sixties led to the rejection of earlier sexual mores held by the society. Sex and love were treated more casually than in earlier lyrics which were characterized by a stronger double standard and "sense of sin." The decline in the Victorian ethic led to an image of communal love rather than middle class monogamy. This image was aided by a more permissive and hedonistic lower class group who entered the record market in a time of relative affluence. A coalition of blacks, lower class hedonists, and rebellious middle class youth altered the tone of American popular music in this way. Honesty was valued and to the lower class "sex was nothing to moan over" while to the middle class rebels it was something to be handled robustly, not euphemized. Mooney contends that romanticism was not completely dead. Bourgeois fidelity was still mentioned occasionally. Unlike Riesman, Mooney does not find lyrics escapist. They meet social conflicts head on, he asserts. This essay is a foundation for understanding the types of popular music prevalent today and the subcultures they represent.

Sociologists Richard Peterson and David Berger believe that changes in music styles were also greatly influenced by 
changes in technology. Lyrics in the twenties, thirties, and forties were oriented to those suitable for air-play and more explicit lyrics of this period were repressed. A growing demand for more explicit lyrics outside the conventional mode is evidenced by the "incursion of underground music into the mainstream" causing the Federal Communications Commission to require radio stations to censor drug oriented Iyrics and other objectional material. They find from their analysis that the diversity of sentiments in lyrics correlates directly with the number of independent units producing songs (4I, p. 298). This reflects the fact that individual songs are often written, produced, and sung by the same performer or group. The decline of the influence of large record companies has enabled many social groups to articulate their particular points of view. Billboard also reports "progressive rock" frequently played on urban FII radio stations. However, their research bureau does not tabulate these according to popularity as it does for the other categories. For the purposes of this paper, rock music will include the "Top Forty" format of this genre. As yet there is no literature on this relatively new musical phenomenon.

\section{Musical Genres}

Evidence of the fact that rock music is important in our society is manifested by the very volume of literature written on the subject. This is both academic and popular. Newspaper 
type publications such as Rolling Stone report on its every aspect. Underground newspapers devote columns to it, record companies advertise it, and the Boston Pops Symphony and other respected orchestras perform it. Probably no musical form has ever descended on a culture with such force as rock music did in the fifties. As a "mulatto" born of black soul and white swing, rock burst upon the relatively calm mid-fifties to infuse this staid era with a driving beat (18, p. 3).

Lyrics were important in early rock, although their nature was often submerged in the music. Early rock lyrics were more often sexually explicit under a cover of symbolism. While "Work With Me Annie" mentioned only "work," its meaning was clear in "let's get it while the getting is good." As Richard Goldstein states in The Poetry of Rock, the use of jargon is part of rock's charm. He asserts that lyricists still bury meanings deep within their songs. Ambiguity was and is an essential component of lyrics because of Federal Communications Commission regulations which prohibit drug and explicit sex references. The awareness of this jargon gives listeners a "solid sense of their own identity" and a sense of their own private music (19, pp. 8-9).

Rock is unique because it is based on the self-expression of the youth culture. Composers directed their lyrics to specific situations instead of amphorous generalities, altering the way which people in the audience reacted to their own experience (17, p. 291). Music and lyrics are so 
indelibly entertwined in the experience of the youth culture that they stamp the listener with a memory of a particular era or experience in his life. Music critic Greil Marcus believes that rock music has the ability to heighten and deepen the present moment $(35, p .291)$. It is a way of responding to Iife which only the generations who have come to maturity during and since the 1950's will ever understand. The incessant, happy repetition of words and music "make the song part of one's mind" (35, p. 295). Rock functions as a translator of society's messages which are captured by metaphor. How much of this metaphor which is so painlessly internalized by the youth culture influences the socialization process?

Rock historian Carl Belz suggests that early rock lyrics were more unconsciously internalized than the more political and sophisticated Iyrics of the sixties. However, rock has been profoundly meaningful since its inception (5). This view is also held by sociologist Irving Louis Horowitz, who believes that so-called "bubblegum" rock is an art form which appeals to younger teenagers because they do not understand the politically sophisticated and symbolically sexual lyrics of later rock music. The nonsensical-danceable music provides entertainment for the sexually unaware and politically naive. Horowitz postulates that rock music may have become so sophisticated in its lyric meaning that it is dying as an art form (23, pp. 459-461). 
Objections to rock music are usually based on its lyric content and not on its musical technique. Music critic Ralph Gleason states that the content of rock lyrics has influenced our "customs and manners" (18, pp. 137-146). Not surprisingly, the John Birch Society has viewed the content of rock music as an attempt to undermine the morality of American youth (1, pp. 151-166). Having demonstrated the effects of rock lyrics on the youth culture in general, we now turn to their proposed effect on sex roles in particular. How are men and women portrayed in rock lyrics?

Goldstein believes that earlier images of the "goddess" and "girlfriend" in rock lyrics have given way to a more complex portrayal, which embraces a humanity which was not previously evident. "No longer are women mere objects of worship or desire in rock. Most put out and few regret it. And their souls won't fit into any text on societal norms" (19, p. 81).

Chris Hodenfield views the evolution of sex roles in rock style as the "howl of the Real Man, a man of a dozen facets and capabilities being both lion and butterfly for his woman" (22, p. 317). Rock musicians and rock music in the sixties led to a less stereotyped male role, he believes, citing changes in male hair styles and dress as well as song lyrics. Two other writers disagree with Hodenfield and each other. Analyzing the Rolling Stones' and Beatles' compositions, Alan Beckett believes that idealization of woman is rampant in 
rock lyrics (4, p. 113). Richard Merton postulates that the Stones in particular celebrate sexual inequality and that in so doing it is held up for ridicule and is "de facto denounced." Further he mentions that one song is about the "confident male" himself having a nervous breakdown. Merton asserts that while the Beatles never strayed far from romantic convention, the Stones have thematically been a dark and "veridical negation" of orthodox pop music (4, p. 117). If sexual exploitation of women as a method of ridiculing sexual inequality is used, its meaning was lost on Marion Meade. Meade asserts that rock degrades women. The clearest indication of how rock music views womankind is in its lyrics. The put-downs are "remarkably multifaceted, ranging from open contempt to sugar coated condescension." Rather than the "goddess" and "girlfriend" viewed by Goldstein, Meade sees women portrayed as "sex crazed animals or all-American emasculators." Rock songs exhibit passive, spiritless women or half-crazy women who are emotionally unstable. Meade also points out that rock is not alone in its degradation of women. Country and soul music also reflect a "rabid machismo" (37, pp. 173-177).

Meade's views are supported by a study reported in Masculine/Feminine or Human? An analysis of sex role stereotyping in contemporary rock music found "the majority of songs dealing only with males. Females were simply of little or no concern." Males were presented as "sexually aggressive, 
non-conforming, somewhat more intellectual, rigid or unmalleable, and egotistical" in one study. In another study of thirty-three popular songs, females were presented as "passive" 66 per cent of the time. The masculine role was more sharply defined than the feminine with males being presented as rational, aggressive, demanding, and breadwinners over 50 per cent of the time. Only one characteristic studied, that of lack of emotionality, was not sustained (12, pp. 43-46).

If rock music is an offspring of country and soul music, it might be well to examine the sire and dam. Historian Bill Malone states that country music has been a commercial item only for the last forty years although it reflects a way of life going back to the very roots of American civilization. Like black music, country-western originated in the South where the agrarian image it portrayed was widely venerated. According to Malone, country music is a way of "viewing or reflecting life." Its dissemination has followed Southern migration to Northern urban centers where the music heard in "homes, churches, cafes, taverns, auditoriums, dance halls, and radio stations" is the "chief cultural staple" of people who "neither understand nor accept any other form." Reflecting on the lower class connotation of country music, Malone finds it worthy of scholarly research because it "both reflects and shapes popular thought." Country music will change, he believes, because Southern culture is 
changing, but in essence it has reflected "isolation, racism, poverty, ignorance and religious fundamentalism" (34, pp. 359-364). Even unpleasant facts of American life need to be portrayed, Malone believes, and music is one viable medium of expression for this.

One researcher, Jens Iund, elaborating on fundamentalism in country music, cites a study by Lewis Killian. The inability of urban churches to play the cohesive social role which they had in the past for Southern migrants to Northern cities led to increased dependence on the tavern, where "country music, both live and recorded, mirrored their distrust of urbanization," Killian stated (31, pp. 82-83).

Country music is widely assumed by researchers to be consumed by working-class whites with rural backgrounds who might be expected to display the conservatism and resistance to change characteristic of the working-class culture. If this music, which of all types depends most on lyric content for its appeal, is so widely accepted, it must be saying something reassuring to its audience. Newsweek claims that the "strong, straightforward lyrics" as well as the simple musical style are factors in country music's popularity. Stagnation in rock music and increased identification with heroes and heroines of country song also contribute to country's ever increasing sales (39).

With what are listeners identifying? A group of researchers examined the rising popularity of country music 
in terms of Iyric themes and audience characteristics. In 1970 there were 650 AM radio stations devoted exclusively to country-western music, reflecting an increase of 569 stations in ten years. Most of the increase occurred in cities outside the South (15, p. 39). The listeners to ten of these stations were surveyed and their characteristics assessed. Apparently such devotees are aged twenty-five to forty-five; white; nationally dispersed (although no survey has been done on actual dispersion); residents of smaller rather than larger cities; less well educated than average (less likely to have attended college, more likely to have completed grade school only); predominantly skilled and semi-skilled blue collar families ( 47.1 per cent as compared with 27.4 per cent of all radio listeners); with income in the five-thousand to tenthousand dollar range (1969 figures). The very poor and affluent were both underrepresented in the sample (15, pp. 47-50).

The same researchers also analyzed the lyrics of two hundred country-western songs published in Country Song Roundup between 1950 and 1970. Themes most prominent were "love, liquor, work, or the passing of the good old ways." Sex roles were not examined per se, but images of men and women formed from these four themes revealed a picture of woman as seen by men as nurturant, revitalizing, in a strong position, often confronting the rival for her lover's affections, or conversely a "cat-like" female with magical 
attributes who delights in sadistic treatment of men, using her sexuality as a tool. Women singers pictured themselves as victimized by men. Dignified and stoic, they held the family and household together (15, pp. 41-43).

Men are viewed in a more complex manner. Often they are revealed as prisoners of law, family, or occupation, who try to fulfill obligations but long for release (15, p. 51). Lyrics extol masculine occupations of the blue-collar variety, such as cowboy, rancher, outlaw, trucker, taxi driver, entertainer, or telephone lineman. The authors note a shift from the agrarian ideal (cowboy, etc.) to other occupations which emphasize the same virtues of strength, freedom, resourcefulness, and self-reliance. Factory work and mining are viewed as "man-killing, routine, and exploitative" occupations which lead to alienation and a desire for escapism (15, pp. 43-44). Loss of a woman's love is shattering in a rapidly changing world. Therefore, it is no wonder that male singers "cry out" for a return to the good old days when there was "dignity in physical labor and the man was master of his household." Men lash out with extra-marital adventures and excessive drinking, which only lead to domestic disintegration. The authors suggest five accommodations which rationalize what they call "promise and denial" in society. The male verbalizes the problem, identifies a scapegoat, espouses fatalism, fantasizes escape, or adheres to a "quiet pride in getting by" (15, pp. 50-52). 
Sex roles in country music are more concerned with an anxious male awash in an eddy of complex social change, dependent on a female for strength and succorance but fearful of this same dependence. Females are pictured in the traditional "good" and "bad" dichotomy which will be discussed in a later portion of this paper. Unlike the females portrayed in rock lyrics, they are confident and vital women, perhaps reflecting the more matriarchal family structure of the lower class or the working-class adherence to the double standard of sexual behavior; e.g., they are good women who are threatened by bad women. Males also reflect the sexual double standard of the working-class. Males are also preoccupied with employment, which may reflect the difficulty of the working-class breadwinner role in a white-collar world. It is expected that both sexes would venerate the agrarian ideal, since this myth of the good old days is rampant as an American culture theme.

Another aspect of these same themes appears in music written for and performed by the black subculture of the United States. The title "Soul" music is usually given to contemporary black music of the popular type. Music critic Arnold Shaw notes that the word soul as applied to black ethnicity did not come to the attention of the mass media until 1967-68. He cites the work of Swedish scholar Ulf Hannerz, who found three themes dominant in soul music: lack of control over the environment; the instability of 
interpersonal relations; and the bittersweet experience. Shaw further states that "soul is black nationalism in pop" and did not become the possession of the black community rather than the expression of it until collapse of the biracial civil rights movement (45, pp. 321-322). To understand Soul, Shaw believes that one must go back to the Blues and the transformation into "urban rhythm and blues."

Charles Keil has done an insightful study of the roots of black music and its transformation in Urban Blues. He traces black music back, not to the blues, but to the music of West Africa from which the blues derives. He cites the "call and response" pattern in Soul Iyrics as deriving from the African pattern. Although Keil's book is primarily about the transformation of the blues to the urban environment, he has some unusual comments on lyrics and their function. Citing a master's thesis by Esther Newton at the University of Chicago, Keil suggests that "the battle of the sexes" is the most striking feature of Negro social structure. Ghetto culture, he states, pits men and women against each other in an antagonism manifested by what Newton calls the "financeromance" equation. Quoting Newton's study, Keil finds men interested in sexual satisfaction and independence and women interested in emotional support and their families. Men call women self-righteous, money-grabbing, treacherous, and domineering. Women simply say all men are no good (27, p. 8). Keil views the battle line shaping up as a matriarch 
with daughters and grandchildren versus the independent black male who seeks allies where he can. As Keil states, "Negro culture exists. . . and within it men and women have found viable identities which can be understood more fully by a study of contemporary black music" (27, p. 29).

The male-female conflict is musically symbolized in the call-response pattern of the dialogue in some instances (27, p. 71). The sexual undercurrent in soul music is strong enough to perpetuate myths of black supersexuality which, Keil states, stem from a difference in candor, style, and the treatment of sexual matters in black lyrics, further complicated by differences between middle-class and lowerclass codes (27, p. 173). Black men are at the bottom of the socio-economic heap in the United States and spokesmen for them are musicians who articulate their problems. While the black lower-class woman might find a man sexually desirable, he is likely to be domestically intolerable, a concept Keil finds related to the blues singer's role in society (27, p. 147). Stated simply, black singers crystallize and synthesize not only their own experience but the experiences of their listeners (27, p. 161). Soul music is strong feelings and emotions shared with others, a kinship of the black community experience.

Black critic LeRoi Jones characterizes this type of black music as "exact replication of the Black Man in the West," an expression of the culture at its most 
un-selfconscious $(26, p .180)$. Jones believes the religious influence of gospel music is significant in the black music of today because the church was one of the few places where the black man had, and still has, full freedom of expression. The Soul music Jones speaks of reflects various aspects of love in lyric form. He, too, finds a gap between black man and black woman--an abyss of separation cried about or shouted about (26, pp. 207-208). The demands, needs, birth, and death of love are presented in practical everyday terms to which listeners can relate and which aid them in assessing their own experiences.

Another black writer points to the oral tradition of Africa in explaining the impact of Soul music. While Europeans depend on pen and ink, African culture has always been transmitted orally by being "spoken, sung, played, and danced." It is this tradition, she states, that one hears pouring out of "window radios and record shops all over the ghetto." Soul music has become a vehicle for black pride and social mobility in a society which has been closed to black aspirations. Through its infusion into contemporary rock music, Soul has permeated all aspects of United States society. It has brought black jargon, entertainers, and most of all, a unique music to a society which has enthusiastically embraced it (30, pp. 98-104). This supports Mooney's thesis that the emergence of the black movement and the affluence of the lower class which was willing to 
spend money on records and radios have changed the content of American music.

Thus the nature of popular songs, Rock, Country-Western, and Soul has affected all United States society, giving it vitality and vibrance. All writers have assessed their particular genres in terms of their reflection and influence on a specific segment of United States society. They have further attempted to demonstrate the influence on the total culture of each type. This review of the literature has sought to establish the scope of popular music in the United States and to demonstrate its relevance for the purpose of studying its influence on the formation of sex role identity. Sex roles are portrayed, consciously or unconsciously, in the lyrics of popular music. Lyrics are listened to by both impressionable adolescents and adults. It is possible, as several of the previous writers have mentioned, that some lyrics are internalized more fully than others because they are associated with a particular time in one's life which has great emotional meaning. As previously stated, Greil Marcus believes lyrics become involved with the "total moment" and will forever recall it to memory when they are played. This effect may be related to what James Joyce called life's "epiphanies," or high points, in which everything is remembered in an emotional context. One of the aspects of life with which this process may be concerned is the courtship process of adolescence and young adulthood. Adolescence is a time 
of formulating sex role identity, and dating and courtship somewhat complicate the process.

\section{The Courtship Process}

The American emphasis on "love" as a dominant theme in the culture is described by Morton Hunt as a determination not to live without it. Hunt considers the American divorce rate a reflection of this value. He believes this is true because Americans will change mates rather than live in an unhappy love relationship. American love, according to Hunt, combines sexual outlet, affectionate friendship, and procreative familial functions in a single relationship. It is no wonder, then, that popular music emphasizes the heterosexual relationship (25, pp. 539-547).

One sociologist, Bolton, believes that adolescents use love relations as a vehicle for dealing with identity problems. The development of a love relationship may precipitate a latent identity problem (8). Leonard Benson, writing in the Family Bond, sees a type of contraceptive-minded, affectionoriented permissiveness developing among the middle class, especially among the professional groups. Benson's research has also led him to conclude that the "love affair," at least as claimed by students in his study, served to better their judgment in mate selection. Benson mentions in this regard that popular songs are not as marriage-oriented as they formerly were, citing two important studies which will 
be discussed in detail in a later section of this paper (6, pp. 116-120).

There is little literature on what males and females desire in a love partner. One researcher, Robert E. Wardell, conducted a study in a middle-class Southwestern suburban community. His two hundred and fifty-seven respondents rated eighteen previously selected traits in importance. It was found that both males and females rated mutual love and attraction as the most important trait in mate selection. Emotional stability and maturity, and dependable character rated second and third. Several differences between male and female responses were noted, however. Males listed chastity and good looks more frequently than did females. Females listed ambition and industriousness, educational background, and good financial prospects more frequently than did males (49). While little generalization can be made from such a limited study, it is interesting to note that the females preferred the more instrumental traits in males while males were more interested in physical aspects such as attractiveness and sexual fidelity. Whether or not these themes are expressed in the lyrics of popular music will remain for analysis. It would appear, initially, that the analysis of the male role in Country-Western lyrics previously cited expressed a real concern for the male role as breadwinner and anxiety over failure in this area. 
Sex Role Stereotyping

\section{The Female Role}

Unfortunately, the real aspects of the male-female relationship have been obscured by the stereotypes so prevalent in United States culture. The stereotyped female has been the subject of much recent sociological investigation. As early as 1950, Viola Klein wrote about female images in United States society. She used Kimball Young's definition of a stereotype as "false classificatory concepts to which, as a rule, some strong emotional feeling, tone of like or dislike, approval or disapproval, is attached--a popular means to simplify, indeed to oversimplify, a complex social reality." Female stereotypes represent what Klein calls the "lowest common denominator of contemporary womankind." In this regard, woman is pictured as homemaker, interested in domesticity, fond of babies, devoted to children, attracted by glamor and romance, and vitally interested in her own appearance. Her success is measured in terms of her relationships with males, not in regard to her own mental and temperamental traits. The pressure of public opinion socializes girls in this pattern to which they conform, according to Klein (28). In the twenty-four years which have elapsed since Klein's analysis, there is little evidence to support a lessening of the rigid female stereotype. 
Psychologists Judith Bardwick and Elizabeth Douvan describe the stereotypical traits applied to women as dependence, passivity, fragility, inner orientation, empathy, sensitivity, nurturance, and subjectivity, among others (3, p. 225). Group differences between the sexes bear out this stereotypic image to a large extent because women from infancy are reinforced for these behaviors, according to Bardwick and Douvan.

Other stereotypes of women in the society have been delineated by Komisar, who found women portrayed either as housekeepers or sex objects in American advertising (29, pp. 304-317). Marjorie B. U'Ren found women are portrayed in school textbooks as passive creatures looking on while males engage in great freedom of movement and choice. Females are helpful, careful, and often indirect in their pursuit of goals. U'Ren mentions that text books are attempting to present reality to students, and this is what is reflected in society (48, pp. 318-328). Wendy Martin found that women in American fiction are pictured as either fallen or virtuous. Women are portrayed as "forlorn, helpless creatures" who can redeem themselves only by foregoing their sexuality. Women who deviate from sexual norms are inevitably punished (36, pp. 329-346).

Janet Saltzman Chafetz discusses feminine stereotypes in Masculine/Feminine or Human? Her research indicates that female stereotypes are manifested in words which have a 
negative emotional connotation over and above their definitions. Thus the female is described as "frivolous," "coy," or "shallow," all of which have negative connotations. Even more positive terms such as "idealistic" and "humanistic" are innocuous when compared to their masculine counterpart of "contributor to society." Chafetz found that even news magazines described females in relation to males, e.g., the leader of India was described as "Nehru's strong-willed daughter." Comic strips portrayed females as passive, domestic, and dependent, while males were aggressive, mechanical, independent, athletic, and nondomestic (12, pp. 47-48). Chafetz goes on to point out that such stereotypes of the female are costly to society in terms of female mental health, with many women hospitalized for mental breakdowns, or turning in their frustration to alcohol, drugs, or promiscuous sex. Such women are made to feel unfeminine and inept if their whole life is not defined in terms of their relation to a husband and children. Such stereotypes also are costly in terms of skills and female potential lost to society because women do not put their talents to use. As Chafetz so aptly states, our society creates a radical dichotomy of human types between people of opposite genders. We are all encouraged to accept a self-definition which may not be congruent with our natural proclivities, and which does not express our human potential. It is a costly procedure for society in many ways (12, pp. 62-66). 
Females are not the only members of society to fall victim to stereotypical sex role behavior. Less has been written about the male stereotype but it is thought to be just as costly as the female one.

\section{Male Stereotyping}

Charles W. Ferguson, in his history of the American male, views the contemporary male as concerned with comparison on a self-imposed standard of masculinity. Acutely and tremulously interested in his own status, the male feels threatened by automation and a world where his competitive spirit can find no outlet (16). Myron Brenton refers to the "masculine straitjacket" which keeps men from expressing emotion and cooperation. Bound to notions of athletic prowess and aggression, males are pushed into the stereotyped role pattern earlier than females, and more stringently pushed at that. Brenton points out the difficulty of the male breadwinner whose wife lives vicariously through her husband's accomplishments and defines her status according to his. The tremendous burden of the male who must support financially and emotionally a female and perhaps several children is revealed in the shorter male lifespan and greater male suicide rate. Males who adhere to the rigid role differentiation may find themselves unable to communicate with their wives. All of these factors lead the American male into a feeling of entrapment, Brenton states. Not only is the male concerned with his role as breadwinner, the change to the nuclear family from the old extended family system places an 
emotional burden on the male. The lover role is emphasized in advertising and folklore. The male is led to have doubts about his masculinity in the recent social emphasis on female pleasure and satisfaction (9).

Sociologist Charles Winick believes that American males are responding to this frustration by a less rigidly defined masculine role. Citing changes toward unisex in clothing, hair styles, and art forms such as music, dance, and painting, Winick postulates that some males and females are retaliating by emphasizing sex role differences, e.g., sex role stereotyping. While some will react rigidly to the perceived threat of unisex, most of society will react favorably to depolarization of the sexes, Winick believes (50, pp. 354-358).

In regard to women in particular, Winick states that "women have largely replaced the male pop singers of earlier decades" $(50$, p. 25). A statement such as this can be easily analyzed by a sample of current songs. Lyrics, he believes, "colored the attitudes that many young people have toward the opposite sex" and the popular music that once conveyed the magic of romantic love now emphasizes non-relational sex (50, p. 31).

The question arises as to just how the sexes are presented in American popular music. One might suppose that since rock music is the voice of the youth culture, the depolarization of the sexes which Winick sees occurring would be manifested there first. As the research of Chafetz has 
concluded, this is not necessarily the case. While no one has as yet analyzed sex roles in contemporary music, a number of researchers have assessed the love-sex and courtship angle of popular music lyrics.

\section{A Review of Lyric Analyses}

In 1944, J. Peatman analyzed popular songs in terms of three categories: happy in love; sad in love; and novelty songs with sex interest. He found that 87 per cent of all popular songs in the year surveyed fit into these three categories (40).

A more extensive analysis was done by Donald Horton in 1957. Using the June, 1955, issues of four song lyric magazines, Hit Parader, Song Hits Magazine, Country Song Roundup, and R.hythm and Blues, Horton subjected 235 different Iyrics to analysis. Of these, 83.4 per cent were conversational songs about love. He used five categories: Prologue, Courtship, Honeymoon, Downward Course of Love, and All Alone. In each broad category, several "scenes" or subcategories were given, such as sentimental appeal as opposed to desperation. In the broad categories, Horton found 21.3 per cent dealing with Prologue, 32 per cent with Courtship, 8 per cent with Honeymoon, 14 per cent with the Downward Course of Love, and 24.7 per cent with All Alone. Horton concurs with Hayakawa's thesis that the listener, especially the adolescent, is presented with a panorama of emotions which he can vicariously enjoy. Horton states that one of the most difficult 
tasks the adolescent has to face is in the learning of interacting and reciprocal roles. The formation of a personally satisfactory conception of himself and his role in relation to the opposite sex is left to the adolescent himself, with an assist from the mass media. Horton observes that adolescents often repeat lines of songs at social gatherings. After the adolescent has completed the cycle with a love object, he must reinterpret its meaning, reducing the abstract to the concrete. In the translation, Horton asserts, songs may promote a sense of sex role identity (24). In 1961 psychologist Alvin Scodel analyzed song lyrics in terms of the presence or absence of romantic love as an American cultural value. Romantic love, as defined by Scodel, is the tendency to exalt the love object while depreciating oneself. Scodel hypothesized that the lyrics of the period 1925-1931 would reflect more emphasis on romantic love than those of the period 1949-1955. Songs were selected for the earlier period from a history of popular music. For the latter period Billboard magazine's rating of most popular songs was used. Scodel used thirteen categories: narcissistic, connubial bliss, nostalgic yearning, phallic playfulness, euphoria produced by love, sadomasochism, infidelity, rejection, yearning for love, protestation of love, seductiveness, inconstancy of love, and other. Later songs reflected the themes of loneliness, unanswered appeals, and psychological trauma should a partner be found. Scodel 
attributes the earlier romantic focus to the European immigrant influence of earlier lyricists, a point also made by Mooney. Indigenous Americans, he believes, were more populist in outlook. He cites economic factors and historical factors such as World War II as having contributed to the depreciation of romantic love (44).

In 1969 sociologist James T. Carey did a double analysis of popular songs. Using the same sample, he first reassessed lyrics in terms of Horton's categories to see if courtship patterns had changed. Secondly Carey looked at the concept of automony as reflected in protest lyrics.

In the first analysis, Carey used Country Song Roundup, Hit Parader, Song Hits Magazine, Billboard, and a San Francisco radio station, KYA, list of hits. Two hundred-twenty-seven songs were analyzed in terms of espousement of "old values" versus "new values." Carey defines as old values those advocating acceptance of conventional social values, romantic notions, fatalistic acceptance of community demands, and those expressing anxiety over social change. New values expressed a more autonomous relationship between the sexes and criticized conventional society. Carey found that only 67.7 per cent of the Billboard sample fit Horton's criteria of courtshipcentered songs. Using only rock lyrics from the sample, Carey assessed heterosexual relationships. He believed that the 1966 songs in his sample encouraged permissiveness without affection and less permanence in relationships. A new pattern 
of courtship had emerged, Carey reported. Changes of values from Horton's study were toward an emphasis on the physical aspects of love. Carey finds that lovers no longer "fall" in love, instead they go out and seek love. The honeymoon stage of Horton no longer implies a permanent relationship. Marriage is seldom, if ever, mentioned. Breakup occurs when the relationship has become unhealthy. Isolation is not a time of desolation but one of self insight and discovery. In discussing sex roles, Carey finds that females are viewed instrumentally and physical attraction is a reason for involvement. Females, Carey states, have been removed from their pedestals. The double standard has given way to a more honest relationship between the sexes (10).

Using only rock lyrics, Carey also analyzed these for evidence of "bohemian" values. Believing that a patterned set of beliefs about society can be discerned in the popular lyrics, Carey finds that the overall preoccupation is with choice. Two major choices are a maximization of freedom in interpersonal relationships and rejection of conventional society. Part of the focus is on the evil which overshadows the individual. In this regard, a basic reconstruction of self and society is urged. Carey then links these beliefs with the revitalization movements which have been described previously in anthropological literature. These beliefs can prepare individuals for collective action. A physical separation from the parent society and construction of a 
utopian world is its logical conclusion. Carey believed that if repressive response to these lyric values is modified, the content of rock protest lyrics would immediately reflect the change (11).

In another content analysis of song lyrics, Richard $R$. Cole assessed the top ten songs of each year, 1960 through 1969, based on the Billboard survey of the top one hundred songs for each year, a list undifferentiated by song genre. A total of ninety-three songs were analyzed, the rest being instrumentals. Using four categories: love-sex, religion, violence, and social protest, Cole determined that love-sex was the dominant theme of the sixties with a total of 71 per cent of the songs being devoted to this subject. Males sang 80 per cent of the love-sex songs. Love was dichotomized as happy or unhappy with only one-third of the songs being assessed as happy. Others were unhappy or balanced between the two. Since males sang most of the songs, females dominated the themes, but Cole notes an ascendance of female domination in the second half of the decade. Cole also indicates more graphic sexual references in this period. Religion was the theme of only two songs. Only 12 per cent mentioned physical violence in any way. Ten per cent of the songs in the latter part of the decade were dedicated to social protest while none in the earlier half were so directed. Cole, unlike Carey, found evidence of a strong positive attitude toward romance. Allusions to drugs, a 
frequent criticism of popular music, were not found by Cole. Deviant messages and popularity evidently do not correlate. Cole, like other communications analysts, believes that song lyrics may influence as well as entertain and inform (13).

In summation, it has been demonstrated that popular songs are an important part of American culture. They are listened to by several differing subgroups. One of the most important of these groups is the large number of adolescents who are at a critical period in life in regard to the formation of sex role identity. Stereotypes which exist in the area of feminine and masculine behavior may also exist in the widely purchased popular song. These songs may then serve to reinforce stereotyped sex roles for those who are forming sex role identity. It is an analysis of this problem which is the subject of this paper.

\section{Male-Female Communication Patterns}

If popular song lyrics may be described, as Horton says, as conversational songs about love, then part of the problem of analysis is the conversation between males and females as communication between the sexes. One book which devotes itself to a sociological analysis of this type of communication is Jessie Bernard's The Sex Game. Bernard divided both males and females into what she called "subsexes" for communication purposes. The unawakened girl belongs to a different subsex from the sexually active girl. Virgins, she points out, miss 
cues, fail to perceive double-entendre messages and points of stories. One might postulate then that song lyrics concerned with the love-sex angle are beamed toward and perceived by sexually active males and females since their manifest content contains many explicit references to sexual activity. It is also possible that such songs are enjoyed by unawakened adolescents for the melody or rhythm of the song.

Further, Bernard believes that upper-class and lower-class females are, for communications purposes, also different subsexes. Males communicate with women on the basis of perceived class differences. It would seem that the same analysis would also apply to class differences between males (7, pp. 14-15). Using literary critic Leslie Fielder's model of the White Maiden and Dark Lady, Bernard explores the madonna and harlot dichotomy which stereotypes females in literature and in religious ideology. The good and bad girl images have been transmogrified, she says, with the Dark Lady assuming the emasculator role and the White Maiden an asexual role ( 7 , pp. 20-21).

Bernard divides male sterotypes into three classes which she calls the Dionysian, Parallelist, and Assimilationist type males. The Dionysian male conforms to the Don Juan stereotype who loves and leaves, wenching his way to further excitement. Parallelists, as the name implies, live side by side with females but do not interact intimately. They are the believers in machismo, and in two separate sexual worlds. 
Only the Assimilationists live in a bisexual world where women are treated as persons. The point of this theory, as Bernard points out, is that men and women communicating to and about each other may be dealing with different people than they imagined. It depends upon which subsex is dealing with whom as to the meaning of communication between producer and consumer. Words in sexual communication can transform "raw sex" into idealized sexuality. Kinsey, Bernard reports, concluded that women responded to words more than to many other forms of sexual stimulation. Men, too, find words seductive but in a different way. Verbal sex may contribute much to the leisure of the future, Bernard believes ( 7 , pp. $34-37)$

Another aspect of male and female communication is based on Eric Berne's concept of emotional units of social action called "strokes," according to Bernard. The need for recognition, affection, and nurturance may be satisfied verbally. Among adults, verbal strokes denote reassurance and acceptance. Words may also denote exploitation and, strategically used, may seduce and conquer ( 7 , pp. 88-89).

Bernard views these strokes, or units of verbal interaction, as being positive and negative. Positive communication raises the status of the other and acts as a cognitive message. Negative communications rejects, shows antagonism, and deflates the other's status (7, pp, 137-144). 
In this way, Bernard states, the sexes learn who they are by "telling one another who they are." The listeners learn who they are and also who the communicators are. "The woman learns who she is both from what she tells the man and from what he tells her" (7, p. 159).

Any test of communication, in Bernard's view, is determined by feedback from the receiver ( $7, p .110)$. In this context, the study of popular song lyrics as male to female and female to male communication may be useful as an example of successful communication. It may be labeled successful because the feedback in the field of popular music can be assessed in terms of popularity. Billboard magazine each year selects the fifty most popular single records in three distinct categories: Country-Western, Easy Listening, and Soul. These songs, by their respective position on the charts, indicate that they have sold records and have been frequently requested for playing on commercial radio stations. It might be inferred from this that the sexes are communicating messages which reflect and perhaps influence sex role identity. 
1. Allen, Gary, "More Subversion Than Meets the Ear," in The Sounds of Social Change, edited by R. Serge $\overline{\text { Denisoff and }}$ Richard $\bar{A}$. Peterson, Chicago, Rand MeNally and Co., 1972.

2. The American Almanac for 1974, "Commercial Broadcast Stations on the Air--States and Other Areas, January 1, 1972," New York, Grosset and Dunlap, Inc., 1973.

3. Bardwick, Judith and Elizabeth Douvan, "Ambivalence: The Socialization of Women," in Woman in Sexist Society, edited by Vivian Gornick and Barbara K. Moran, New York, Basic Books, Inc., 1971.

4. Beckett, Alan and Richard Merton, "Stones/Comment," in The Age of Rock: Sounds of the American Social Revolution, edited by Jonathan Eisen, New York, Vintage Books, A Division of Randon House, 1969.

5. Belz, Carl, The Story of Rock, New York, Oxford University Press, 1972 .

6. Benson, Leonard, The Family Bond: Marriage, Love, and Sex in America, New York, Random House, 1971.

7. Bernard, Jessie, The Sex Game, Englewood Cliffs, New Jersey, Prentice Hall, Inc, , 1968.

8. Bolton, Charles D., "Mate Selection as the Development of a Relationship," Marriage and Family Living, XXIII (August, 1961), 234-240.

9. Brenton, Myron, The American Male, New York, CowardMcCann, Inc., 1966.

10. Carey, James T., "Changing Courtship Patterns in the Popular Song," American Journal of Sociology, LXXIV (May, 1969), 720-731. 
12. Chafetz, Janet Saltzman, Masculine/Feminine or Human? An Overview of the Sociology of Sex Roles, Itasca, IIlinois, F. F. Peacock Publishers, Inc., 1974.

13. Cole, Richard R., "Top Songs in the Sixties, "American Behavioral Scientist, XIV (February, 1971), 389399 .

14. Coleman, James Samuel, The Adolescent Society: The Social Life of the Teenager and Its Impact on Education, New York, The Free Press, 1961.

15. Dillaggio, Paul, Richard A. Peterson, and Jack Esee, Jr., "Country Music: Ballad of the Silent Majority," in The Sounds of Social Change, edited by R. Serge Denisoff and Richard A. Peterson, Chicago, Rand MoNa.ly and Co., 1972.

16. Ferguson, Charles Wright, The Male Attitude, Boston, Littie, Brown, and Co., 1966.

17. Gillett, Charlie, The Sound of the City, New York, Outerbridge and Dienstfrey, 1970 .

18. Gleason, Ralph, "A Cultural Revolution," in The Sounds of Social Change, edited by $R$. Serge Denisoff and Richard A. Peterson, Chicago, Rand McNally and Co., 1972 .

19. Goldstein, Richard, editor, The Poetry of Rock, New York, Bantam Books, 1969.

20. Greenburg, Bradley S., and Brenda Dervin, Use of the Mass Media by the Urban Poor, New York, Praegar Publisher, 1970 .

21. Hayakawa, S. I., "Popular Songs vs, the Facts of Life," in Mass Culture: The Popular Arts in America, edited by Bernard Rosenberg and David Manning White, Glencoe, Illinois, The Free Press, 1957.

22. Hodenfield, Chris, "The 60's Recollected: An Incisive Report, " in Mass Media: Forces in Our Society, edited by Francis and Ludmila Voelker, New York, Harcourt Brace Jovanovich, 1972.

23. Horowitz, Irving Louis, "Bubblegum Anyone?" in Mass Culture Revisited, edited by Bernard Rosenberg and David Mannin White, New York, Van Nostrand Reinhold Co., 1971. 
24. Horton, Donald, "The Dialogue of Courtship in Popular Songs," American Journal of Sociology, LXII (Nay, 1957), 569-578.

25. Hunt, Morton, "The Age of Love," in America as a Mass Society, edited by Phillip olson, Glencoe, IIlinois, The Free Press, 1963.

26. Jones, LeRoi, Black Music, New York, W. Morrow, 1967. 27. Keil, Charles, Urban $\frac{\text { Blues, Chicago, The University of }}{\text { Chicago Press, } 1969 \text {. }}$

28. Klein, Viola, "The Stereotype of Femininity," Journal of Social Issues, VI, No. 3 (1950), 3-9.

29. Komisar, Lucy, "The Image of Woman in Advertising," in Woman in Sexist Society, edited by Vivian Gornick and Barbara K. Moran, New York, Basic Books, Inc., 1971 .

30. Larkin, Rochelle, "The Soul Message," in The Sounds of Social Change, edited by R. Serge Denisoff and Richard A. Peterson, Chicago, Rand McNally and Co., 1972 .

31. Lund, Jens, "Fundamentalism, Racism, and Political Reaction in Country Music," in The Sounds of Social Change, edited by R. Serge Denisoff and Richard A. Peterson, Chicago, Rand McNally and Co., 1972.

32. Luthe, Heinz Otto, "Recorded Music and the Record Industry," International Social Science Journal, $\mathrm{XX}$, No. $4(1968), 656-666$.

33. McLuhan, Marshall, Understanding Media: The Extensions of Man, New York, New American Library, Inc., 1964.

34. Malone, Bill, Country Music U.S.A., Austin, University of Texas Press, 1968.

35. Marcus, Greil, "Who Put the Bomp in the Bomp De-Bomp De-Bomp?" in The Popular Arts in America, edited by William M. Hammel, New York, Harcourt Brace Jovanovich, Inc., 1972.

36. Martin, Wendy, "Seduced and Abandoned in the New World: The Image of Woman in American Fiction," in Woman in Sexist Society, edited by Vivian Gornick and Barbara K. Moran, New York, Basic Books, Inc., 1971 . 
37. Meade, Marion, "The Degradation of Women," in Sounds of Social Change, edited by $R$. Serge Denisof $f$ and Richard A. Peterson, Chicago, Rand McNally and Co., 1972 .

38. Mooney, H. F., "Popular Music Since the 1920's: The Significance of Shifting Taste," in The Popular Arts in America, edited by William M. Hammel, New York, Harcourt Brace Jovanovich, Inc., 1972.

39. Newsweek, June 18, 1973, pp. 64-72.

40. Peatman, J., "Radio and Popular Music," in Radio Research: $1942-43$, edited by Paul Lazarsfeld and F. Stanton, New York, Duel1, Sloan and Pearce, 1944.

41. Peterson, Richard A., and David G. Berger, "Three Eras in the Manufacture of Popular Music Lyrics," in The Sounds of Social Change, edited by $R$. Serge Denisoff and Richard A. Peterson, Chicago, Rand MeNally and Co., 1972.

42. Riesman, David, "Listening to Popular Music," in Mass Culture: The Popular Arts in America, edited by Bernard Rosenberg and David Manning White, Glencoe, Illinois, The Free Press, 1957.

43. Robinson, John P., and Paul M. Hirsh, "Teenage Response to Rock'n'Roll," in The Sounds of Social Change, edited by $R$. Serge Denisoff and Richard A. Peterson, Chicago, Rand McNally and Co., 1972.

44. Scodel, Alvin, "Changes in Song Lyrics and Some Speculations on National Character," Merrill-Palmer Quarterly, VII (1961), 39-47.

45. Shaw, Arnold, "Soul Is," in The Popular Arts in America, edited by William M. Hammel, New York, Harcourt Brace Jovanovich, Inc., 1972.

46. Time, November 24, $1967, \mathrm{pp} .35-39$.

47. Time, May 6, 1974, pp. 51-55.

48. U'Ren, Marjorie B., "The Image of Woman in Textbooks," in Woman in Sexist Society, edited by Vivian Gornick and Barbara K. Moran, New York, Basic Books, Inc., 1971 .

49. Wardell, Robert E., "Priorities in Mate Selection: What People Look For in an Ideal Mate," unpublished paper read before the Southwestern Social Science Association, Dallas, Texas, March 28, 1974. 
50. Winick, Charles, The New People: Desexualization in American Society, New York, western Publishing Co., 1968 . 


\section{METHODOLOGY AND RESEARCH DESIGN}

As previously stated, it is possible that popular songs influence the socialization process, especially in the adolescent. Since sex role identification is a major component of the socialization process, it is of interest to determine what sex role traits are reinforced in popular song lyrics. This has not been studied previously. Further, since John P. Robinson and Paul M. Hirsch (11, pp. 228-230) found that social class and ethnic identity influenced the perception of song lyrics in their teenaged sample, it is desirable to study popular lyrics which are differentiated as to musical genre. In this way, male-female communication can be assessed in terms of ethnic and subcultural differences. Several researchers including Hirsch recommend the method of content analysis for studying popular lyrics (8).

\section{Content Analysis}

As a methodology, content analysis has been defined as "a research technique for the objective, systematic, and quantitative description of the manifest content of communication" (2, p. 18). It is also a process for transforming 
communication content into data that can be summarized and compared $(9, p, 3)$. Content analysis has been compared to a rake with varying sets of teeth with which the researcher combs a particular area of communication in which he has an interest (4, p. 6). It is generally agreed that as a research tool content analysis has many applications and some limitations.

Since its inception as a research tool, content analysis has had many uses. At some time almost every kind of verbal communication content has been studied. Journalists have utilized this approach to assess newspaper coverage since the beginning of the Twentieth Century. During World War II governments used content analysis to determine the attitudes present in propaganda and to determine trends in this area. Content of radio programs, films, television programs, books, magazines, personal letters and diaries, and even private conversations has been subjected to scrutiny. In recent years, content analysis has been improved by the use of the computer. There are, however, many areas of content too subtle to be programmed into a computer. The need for the personal touch of the analyst still exists. It has been suggested that content analysis might well be applied to issues that are outside of normal awareness--that is, to plumb unconscious attitudes and traits underlying human behavior as evidenced in communication (4, p. 35). As such, 
it is similar to the psychobiography currently used as an approach to understanding historical figures.

Content analysis has advantages over other methods of research. First of all, it uses available data. Our highly verbal society each year produces communication content in prolific abundance. This communication is a storehouse of political, historical, societal, and psychological data. The researcher is faced with the mammoth problem of selecting the topic to be studied and the methods to be utilized. One is limited only by the human imagination in what may be analyzed and in what ways. Recently, content analyses have been made of such diverse subjects as cartoons, photographs, and children's drawings (9, p. 22).

A second advantage of content analysis is that the communication is not produced for purposes of research. Unlike the survey method, the data is collected without the knowledge of the producer. It is presumed that such data are therefore more "natural" than data gathered under other circumstances.

One advantage of content analysis is in the certainty of having one's data in black and white. Carney says that only when the researcher has all the facts before him can he see which are emphasized most, which least, and which are not emphasized at all (4, p. 17). An omission may be more important than a high frequency of occurrence of a symbol. 
Further, content analysis broadens the scope of the researcher. Analysis of documents may produce important data about a period long past. Such information may yield insights which have been overlooked previously. This method may also be used to assess changes over time. For example, sex roles may be studied in United States magazine fiction and popular songs in the present and compared to sex roles depicted in the same media fifty or one hundred years past. Changes in such attitudes can then be documented. In spite of language barriers, content analysis may even be used in cross cultural studies.

There are, however, difficulties with this method of investigation. It has been alleged that content analysis is more art than science, due to the subjective nature of some studies. Conversely, it has also been alleged that content analysis is overly concerned with mere quantification of data. This is a valid criticism. The quantitative requirement has been deemed essential by both proponents and critics of content analysis. There are differences of opinion which cloud the quantitative issue. What does the frequency with which symbols appear actually denote? It is believed that frequency is a valid index of concern, preoccupation, and intensity (9, pp. 5-12). The presence or absence of a symbol, rather than the frequency with which it appears may also be a valid approach to analysis. However, some form of numerical data is necessary for several reasons. 
One may state conclusions with a degree of precision not possible in a qualitative study. Numerical data lend themselves to statistical analysis.

There is not a strict dichotomy between qualitative and quantitative analyses. It has been stated that the qualitative and quantitative aspects of analysis fall along a continuum and that most analyses require both $(2, \mathrm{pp}$. 114134). Especially in the area of popular music analysis, the researcher leaning heavily toward quantitative analysis may run the risk of missing important observations which do not fit into a priori categories (6, p. 179).

Another criticism of this methodology is that it may be performed on symbols which have a deeper meaning than that of the manifest content of the document. Here, frequency is not the issue. A danger exists that the researcher may inject his own values to an extent that the research becomes a personal essay. Most researchers believe that only manifest attributes of documents should be coded. Inference about latent meanings may be permitted if corroborated by independent evidence (9, pp. 13-14).

Another criticism of content analysis is that such documents reflect only the views of those producing them. This does not necessarily imply that the views are held by those receiving the communication. The researcher should therefore seek out documents whose reception can be determined if he wishes to infer characteristics of the receiver from material produced. 
The researcher contemplating a content analysis should be concerned with the issues of reliability and validity. Reliability is determined by the consistency of independent but comparable measures of the same data (12, p. 167). Reliability in content analysis is established when two or more coders classify material in the same categories. Simplification of categories and units facilitates reliability (2, p. 174). Forms of reliability testing used in other areas of research, such as split-half, test-retest, or equivalent forms may be used. AlI researchers agree that more than one coder should always be used. A reliability index of .67 to .99 should be obtained. This is not to say that studies with lower reliability indices should be discarded. Usually they need only to have the categories refined. The reliability depends upon the analyst's ability to formulate categories which are clearly defined (9, p. 136).

Validity refers to the extent that a method actually measures what it is supposed to measure. Validity of an analysis is determined by category definition also. One writer declares that careful and judicious selection of categories will take care of the matter of validity completely (2, p. 171). Simplification also increases validity. If one's study is to count word frequencies, validity is not much of a problem. Where categories are 
highly abstract and extremely complex, validity may be a subject of great concern.

There are several distinct problems with the analysis of song lyrics. In all cases the context of the song must be considered. Meaning of jargon in lyrics must be known if a valid analysis is to be made. The "musical package" must be considered also. For example, R. Serge Denisoff states that "Born Free" was originally the theme of a film about a lioness. It was later recorded by a black group as an anthem of black pride. The researcher must be careful to view the lyric in the context of the time in which it was written. In the context of performance a lyric may take on another meaning. For example, the conservative rhetoric of "Okie from Muskogee" has become quite popular with the counterculture group it sought to denigrate. Further, the context of consumption may vary, as previously stated, according to the sophistication of the listeners (7, pp. 7-8).

Once the problem to be analyzed has been formulated, category selection becomes of paramount importance. Bernard Berelson describes the necessity of careful category selection by stating that "content analysis stands or falls by its categories" (2, p. 147). Content analysis is no better than its system of categories. Several general types of categories have been suggested based on the nature of the material to be analyzed. 
The theme is a category which is general in scope. It might be called the main idea of the document. Berelson says this is one of the most useful units of content analysis. He also cautions that it is one of the least reliable if the broad subject category is complex (2, pp. 138-139). Documents may also be analyzed according to the direction of presentation of the symbol. As Berelson states, the basic question here is whether the communication is for or against the particular subject, or neutral toward it. For this type of analysis, Berelson recommends Kaplan and Goldsen's criteria for determining direction of presentation (2, pp. 150-151). Another category for analyzing documents is one for the determination of traits present. As it is usually formulated, this analysis is based on certain psychological traits, ordinary personal characteristics, and other ways of describing people (2, pp. 155-156).

Categories should reflect the purpose of the study, be exhaustive, mutually exclusive, independent, and derived from a single classification principle (9, p. 95). A researcher must define clearly the variables involved and specify explicitly the indicators which determine whether a datum falls into a specific category. A set of categories is exhaustive when all relevant items are capable of categorization. Mutual exclusiveness stipulates that a datum be placed in a single category. Independence of assignment means that a datum should be placed in a category without 
regard for the amount of data already placed in this category. In other words, each datum is to be considered separately and alone. Ole R. Holsti points out the difficulty of this. But assignment of a datum into a category should not affect the classification of the data to follow (9, p. 100). The researcher should confine each level of analysis to a conceptual framework. For example, theme and direction should not be analyzed at the same time. Two separate analyses would be required. Content analysis should proceed on a general to specific continuum. Larger units may be broken down into more specific sub-categories.

Units of analysis may be as small as one word or as large as an entire document. Units as small as sentences or paragraphs are not recommended because they do not lend themselves easily to a single category (9, p. 117). These smaller units are not efficient since they tend to duplicate larger units and classification of them requires more research time.

Once the problem has been defined and categories selected, sampling of the data becomes an important decision. In content analysis this is especially problematic since the universe of communication is likely to be extremely large. Such research must necessarily sample the universe very selectively in order to assure a sample representative of the universe. Sampling should follow guidelines set down for behavioral research. For this reason, random sampling 
is often used, e.g., every nth issue of a periodical. Samples may be clusters or purposive as well. At all times the researcher must be on guard against simply reducing the data to manageable size. Sampling should have a plan to insure reliability of the study. Generally sampling must concern the titles to be analyzed, which issues of same to be included, and what content of the issues is deemed relevant. An analysis of popular songs, then, must take all of these factors into consideration. Sampling should be carefully planned, categories formulated, and the units to coded determined.

\section{Research Design}

\section{Sampling}

Since research has documented selective perception of popular music on the part of various cultural and ethnic groups, a sample of each genre of music is necessary to determine differences and similarities among groups. Sociological literature documents differences in sex roles in middle-class, working-class, and black subcultures. A sample of music taken from the type thought to appeal to these three groups, then, may yield data about male and female roles as presented in song lyrics.

To insure that the song lyrics to be sampled reflect the acceptance of the groups in question, some sort of index of popularity is necessary. Otherwise, a sample of lyrics 
might reflect only the views of those producing them. It is presumed that sales and frequency of air play reflect public acceptance. A sample of yearly popularity is more desirable than a monthly sample, since it is possible that seasonal variations exist.

Each year the Research Bureau of Billboard magazine tabulates the single records which have achieved greatest popularity in three musical genres: Easy Listening, Soul, and Country-Western. These forty-five-rpm singles are often cuts taken from long-playing albums. They have sold well throughout the year and have been played frequently on the air. For the year 1973, this popularity was assessed by Billboard from November 25, 1972, through November 17, 1973. The lists themselves were published in the December 29, 1973, issue of Billboard.

This sample was chosen for the study because it differentiates among musical genres and because it reflects public acceptance of the records. The top fifty songs in each genre were chosen for analysis. This yielded a total of one hundred and fifty-one songs, since there was a tie in the Country-Western group. The list provides the name of the song, the artist, the recording company, and the distributor. Lyrics to the songs were obtained in various ways. Books published by Charlton Publishing Company, including Song Hits, Country Song Roundup, Hit Parader, Rock and Soul, and the Annuals published for each genre, were used. Over 
one hundred of the lyrics were obtained from these publications. It was noted that these lyric books contain a high percentage of love songs. The remainder of the lyrics were obtained from records, tapes, and sheet music. Those lyrics taken from records and tapes were played a minimum of five times each to determine the correct lyrics.

Five songs were "cross-overs" from one genre to another. Four of these were recorded by the same artist. Two records crossed from the Country list to the Easy Listening, and two from the Soul list to Easy Listening. One song, recorded by different artists, appeared on the Country and the Easy Listening lists. There were no cross-overs from Soul to Country or vice versa. These songs were kept in the sample and analyzed in the genres in which they were listed. The fact that the songs appeared in the top fifty rating was indicative of their popularity. Therefore, the values they represent were analyzed in the respective genres in which they appeared. Iyrics thus obtained were then subjected to content analyses based on methods suggested in the previous section of this chapter.

\section{Limitations}

These songs reflect the sales and frequency of air play of forty-five-rpm records. The consumers of such records may differ in some way from the consumers of record albums. Such consumers may be less affluent or younger than purchasers 
of albums. Radio stations play the particular songs requested, frequently using the forty-five-rpm records, however.

The songs were analyzed in terms of male or female attributes on the basis of the gender of the performer. It is possible that these same songs may be recorded by artists of the opposite gender. It is assumed that the popularity of the song by a particular performer is indicative of public acceptance. There were no songs in the sample which had been recorded by a male and a female artist.

The subcultural and ethnic generalizations about the appeal of lyrics to certain groups are subject to limitations. There is some evidence to support the statement that Country music appeals primarily to white working-class people. However, Country music is presently enjoying national popularity as evidenced by articles previously cited. It is obviously enjoyed by people other than working-class whites.

No studies are available to determine what type of people purchase Soul records and listen to radio stations playing soul music. It is assumed for purposes of this study that such music appeals most frequently to the urban black subculture. However, other ethnic groups may also enjoy Soul music and their preferences may be reflected in popularity ratings to an extent that is unknown.

The Easy Listening genre contains both rock and romantic music. It is assumed that the romantic music has a middleclass appeal. The rock music is thought to appeal to 
middle-class youth, but may also be cross-cultural in its appeal. The audience in this genre is most likely to be diverse in both age and social class composition.

Although only two of the one hundred and fifty-one songs are instrumentals, it is realized that lyrics play a varying role in determining song popularity. While lyrics are important, they are only component of the total musical package. The analyses are performed and generalizations made with these limitations noted.

\section{Analysis of Performers}

To determine the accuracy of statements that there is an increase in women performers and to determine for future analyses the gender of the performers, an analysis is necessary. Not all songs are performed by male and female soloists. Some are performed by mixed groups or groups of one sex or the other. The songs are analyzed using the Billboard list to ascertain which are performed by male soloists, males with group backing, all male groups, female soloists, females with group backing, female groups, mixed groups, and instrumentals. When doubt exists as to gender or group composition, pictures and published material about the artists is consulted. The results are stated in percentages.

\section{Analysis of Themes}

The main subject of each song is analyzed to determine whether the song should be classified as Heterosexual, 
Personal, Social Values, Religious, Nostalgic, or Novelty. Full definitions of these categories are appended (Appendix B): Other researchers previously cited have stated percentages of songs devoted to the love-sex theme. This category is used to compare the songs of 1973 with those of previous studies with respect to the love-sex theme. The Heterosexual. category is also used as a basis for further analyses of songs to determine love relationships and male and female traits. Some songs are simply personal statements by the singer about problems or experiences in life. This category is useful in assessing differences in these problems and experiences between males and females and among genres. The social values represented in popular lyrics may be compared to the previous study by cole to determine if differences in the number of songs devoted to this theme are apparent. Cole also noted a small number of religious songs. A renewed interest in religious values among some groups may point out differences between this analysis and Cole's study. A current cultural theme is nostalgia. This category is included to determine if this cultural theme is reflected in popular lyrics. Some songs are instrumentals and others are nonsensical. This category is included to determine the number of songs devoted to this theme. Frequency of classification in each category is stated by percentage. Both a total for each category and percentages for each genre are given. This facilitates comparison among musical types. 


\section{Analysis of Love Relationships}

one researcher categorized songs with the love-sex theme as happy or unhappy and found that only one third of the songs were happy. In order to test this conclusion and to determine whether male or female performers appear more happy or unhappy in the love relationship, an analysis is performed to categorize relationships. Those songs performed by female artists and those performed by male artists are analyzed to determine if the relationship is satisfactory. Those songs depicting a relationship which is predominantly unhappy are categorized as Love Lamented. Songs which depict a relationship as predominantly happy are categorized as Love Lauded. If equal lines of the song are devoted to happy and unhappy aspects of the relationship, it is categorized as a balanced one. Obviously songs with the theme of male-female relations will be used for this analysis. All other categories of songs are excluded.

\section{Analysis of Address}

In order to investigate the way in which males and females communicate in popular lyrics, an analysis is necessary to ascertain which songs are directed to females and which are directed to males. Those songs previously categorized as Heterosexual in theme are further analyzed by dichotomizing them by gender. Songs sung by male performers and addressed to a love object are presumed to be songs directed to females. 
Songs performed by females and directed to a love object are presumed to be songs directed to males. Thus the songs are categorized as being directed to a female, being about a female, being directed to a male, or being about a male. Songs in the heterosexual category which are duets, are about two other people, or are about love in general are excluded from this analysis. This analysis also provides a basis for the following study.

\section{Analysis of the Direction of Presentation}

As suggested by Berelson (2), communication may be analyzed to determine if the symbol is presented positively, negatively, or neutrally. Berelson recommended a set of criteria developed by Kaplan and Goldsen for determining the direction of presentation. In this analysis, the symbol is coded as being presented positively, positively with qualification, negatively, negatively with qualification, or neutrally. Kaplan and Goldsen also provide a category for no direction of presentation. Since all lyrics not previously coded as being concerned with a male or a female are excluded, this last category is not necessary. A more detailed definition of Kaplan and Goldsen's criteria is provided in the appendix (Appendix B). Songs performed by males are analyzed to ascertain the way in which the female love object is presented. Songs by female artists are analyzed to determine how the male love object is presented. 
A table of percentages is provided to illustrate male and female presentations for the total sample and for each genre.

\section{Analysis of Sex Roles}

Those songs previously categorized as heterosexual in theme are subjected to further analysis to investigate the sex roles present in each song. Judith $\mathbb{M}$. Bardwick and Elizabeth Douvan (I) refer to the stereotypical traits of females as being dependent, passive, nonaggressive, fragile, receptive, and unable to take risks. Further Janet Saltzman Chafetz (5, p. 45) reports studies in which stereotypical female traits of domestic, passive, flirtatious, insecure, inconsistent, idealistic, and dependent are assessed in the lyrics of thirty-three popular songs. Females in her studies conformed to all these traits in varying percentages. Other writers have mentioned female vanity and the idea of the female as a sex object rather than a person. Because of their association with the female stereotype, six traits are chosen for analysis of the female sex role in this analysis. These traits are supportive, inconsistent, submissive, dependent, hesitant, and beautiful. A more detailed definition of each trait is provided in the appendix (Appendix B).

Bardwick and Douvan (1) further describe stereotypical male traits as independent, aggressive, competitive, assertive, active, objective, rational, confident, and 
unemotional. Chafetz $(5, \mathrm{p} .46)$ reports studies in which stereotypical male traits of breadwinner, aggressive, unemotional, rational, and demanding are investigated to determine the extent to which males in thirty-three popular songs conform to these traits. It was concluded that males in these songs conformed to four of the traits. The exception was the trait of unemotionality. Because of their association with the male stereotype, six traits were chosen for investigation of the male sex role. These traits are aggressive, independent, demanding, consistent, confident, and active. These traits are defined in more detail in the appendix (Appendix B). Further, the male and female traits may be paired for purposes of comparison.

This analysis is conducted by examining each of the lyrics previously defined as Heterosexual in theme to determine if the subjects depicted in these songs conform to the male and female traits. If the trait is not mentioned in the song, a percentage is tabulated for songs in which the trait is not present. Thus each of the twelve male and female traits appears in a table along with the percentage of songs in which the male and/or the female conform to the trait. If the subject is portrayed as conforming to an opposite trait, e.g., a submissive male, he is coded as not conforming to the trait. Percentages are stated for each trait showing the number of songs in which subjects conformed, or the trait is not mentioned. 
Comparisons based on percentages of conformity and nonconformity are then made between males and females in general and between males and females among genres. Differences in the female role among genres are also compared. Male differences in conformity to traits among genres are also assessed.

Reliability of this study is determined by one other coder and a reliability index is stated (Appendix C). The unit of analysis is the entire song. The six analyses conducted are designed to yield information about the manner in which males and females are presented in contemporary popular lyrics. Within the stated limitations of this study, the information gathered from these analyses may be used to assess the possible effect on the socialization process of male and female roles depicted in popular lyrics. 


\section{CHAPTER BIBLIOGRAPHY}

1. Bardwick, Judith M. and Elizabeth Douvan, "Ambivalence: The Socialization of Women," in Woman in Sexist Society, edited by Vivian Gornick and Barbara $\bar{K}$. Moran, New York, Basic Books, Inc., 1971.

2. Berelson, Bernard, Content Analysis in Communication Research, Glencoe, Illinois, The Free Press, 1952.

3. Budd, Richard W., Robert K. Thorp, and Lewis Donohew, Content Analysis of Communications, New York, The Macmilian Company, $196 \overline{7}$.

4. Carney, Thomas F., Content Analysis: A Technique for Systematic Inference from Communications, Winnipeg, Canada, University of Manitoba Press, 1972.

5. Chafetz, Janet Saltzman, Masculine/Feminine or Human? An Overview of the Sociology of Sex Roles, Itasca, Illinois, F. E. Peacock Publishers, Inc., 1974.

6. Denisoff, R. Serge, and Richard A. Peterson, "Changing Musical Tastes," in The Sounds of' Social Change, Chicago, Rand McNal1. $\mathrm{Co}_{0.1972}$.

7. "Theories of Culture, Music, and Society, "in The sounds of Social Change, Chicago, Rand McNally Co. , 1972.

8. Hirsch, Paul M., "Sociological Approaches to the Pop Music Phenomenon," The American Behavioral Scientist, XIV (January/February, 1971), 37 1-388.

9. Holsti, Ole R., Content Analysis for the Social Sciences and Humanities, Reading, Massachusetts, AddisonWesley Publishing Co., 1969.

10. Kracaur, Siegfried, "The Challenge of Qualitative Content Analysis," Public Opinion Quarterly, XVI (winter, 1952-1953), 631-642.

11. Robinson, John P. and Paul M. Hirsch, "Teenage Response to Rock'n'Roll," in the Sounds of Social Change, edited by $R$. Serge Denisoff and Richard A. Peterson, Chicago, Rand McNally and Co., 1972. 
12. Sellitz, Claire, Marie Jaboda, Morton Deutsch, and Stuart W. Cook, Research Methods in Social Relations, New York, Holt, Rinehart and Winston, 1959 . 


\section{ANALYSES OF PERFORMERS, THEMES, AND LOVE RELATIONSHIPS}

\section{Performers}

Since the other proposed analyses of data rest on the determination of the gender of the performer, an analysis is necessary to determine which songs are performed by males and which are performed by females: Not all songs are performed by soloists. Many are recorded by a lead singer backed by a group composed of one sex or mixed. For further research purposes, those songs recorded by a single male, male with group backing, and all-male group will be classified as male performers. Those songs performed by a single female, female with group backing, or all-female group will be classified as female performers. Those recorded by groups mixed in gender will not be analyzed in categories which depend on gender.

Overal1, 68 per cent of the songs in the sample are performed by males, 27 per cent by females. In addition, 3.3 per cent are performed by mixed groups, and 1.3 per cent are instrumental (Table I). There are differences among genres, however. In the Easy Iistening group, 66 per cent 
of the songs are performed by males, while in the Soul genre 78 per cent are performed by males. Country-Western male singers perform only 61 per cent of the songs in that genre.

\section{TABLE I}

TYPE OF PERFORMER BY TYPE OF MUSIC

\begin{tabular}{|c|c|c|c|c|c|c|c|c|}
\hline Performer & \multicolumn{2}{|c|}{$\begin{array}{l}\text { Easy } \\
\text { Listening }\end{array}$} & \multicolumn{2}{|c|}{ Soul } & \multicolumn{2}{|c|}{$\begin{array}{l}\text { Country- } \\
\text { Western }\end{array}$} & \multirow{2}{*}{\multicolumn{2}{|c|}{$\frac{\text { Total }}{\text { Tol( }(46 \%)}$}} \\
\hline Male Soloist & 25 & $(50 \%)$ & 17 & $(34 \%)$ & 28 & $(55 \%)$ & & \\
\hline $\begin{array}{l}\text { Male with Group } \\
\text { Backing }\end{array}$ & 3 & $(6 \%)$ & 3 & $(4 \%)$ & 3 & $(6 \%)$ & 8 & $(5 \%)$ \\
\hline All-Male Group & 5 & $(10 \%)$ & 20 & $(40 \%)$ & 0 & $(0 \%)$ & 25 & $(17 \%)$ \\
\hline Female Soloist & 12 & $(24 \%)$ & 8 & $(16 \%)$ & 18 & $(35 \%)$ & 38 & $(25 \%)$ \\
\hline Female with Group & 0 & $(0 \%)$ & 3 & $(6 \%)$ & 0 & $(0 \%)$ & 3 & $(2 \%)$ \\
\hline All-Female Group & 0 & $(0 \%)$ & 0 & $(0 \%)$ & 0 & $(0 \%)$ & 0 & $(0 \%)$ \\
\hline Male and Female & 3 & $(6 \%)$ & 0 & $(0 \%)$ & 2 & $(4 \%)$ & 5 & $(3 \%)$ \\
\hline Instrumental & 2 & $(4 \%)$ & 0 & $(0 \%)$ & 0 & $(0 \%)$ & 2 & $(1 \%)$ \\
\hline Total & 50 & $(100 \%)$ & 50 & $(100 \%)$ & 51 & $(100 \%)$ & 151 & $(99 \%)$ \\
\hline
\end{tabular}

Female performers account for 35 per cent of the CountryWestern performers but only 24 per cent of the Easy Iistening group. Twenty-two per cent of the songs in the Soul genre are performed by females. Six per cent of the Easy Listening songs, 4 per cent of the Country songs, and none of the Soul songs are performed by mixed groups. The all-male group, a fixture in the popular music scene since the advent of rock 
music, is evidently on the decline in the single record category of Easy Listening and is non-existent in the Country group. However, male groups account for 40 per cent of the Soul singers, single males for 34 per cent, and males with group backing for only 4 per cent. Country singers do not seem oriented to groups, since there are no all-male groups and only three songs recorded with a male lead and group backing. There are no female groups in any genre. only in the Soul genre is there a female lead singer with group backing, which accounts for 6 per cent of the Soul group. These singers have several recordings on the list.

The dominance of male performers in the music field is not surprising. This has been the case for many years. The heavy concentration of male performers in the Soul genre is somewhat surprising, however. It is possible that since this area of popular music has been a vehicle for black mobility when other avenues of mobility were closed, black males who have talent are attracted to the music profession in great numbers. Certainly it has proved a lucrative occupation for many performers, and is attractive to black males for this reason. It also provides black males with the recognition and sense of achievement which they have not found to such a great extent in other professions where they may have been regarded as tokens.

The music profession may also be a vehicle for social mobility for working-class females who, like black males, 
are powerless in other areas. There is evidence to support the fact that several of the more popular Country-Western female singers are working-class females who have received no professional musical training ( $1, \mathrm{p} .27$; $3, \mathrm{p} .65$ ). Country-Western music has a tradition of female ballad singers going back to its earliest days. However, the number of Country-Western female singers is surprising when compared to the low number of Soul female singers.

\section{Themes}

Six categories are used to classify popular songs by theme. The Heterosexual category deals with male-female relationships. Personal songs are those in which the performer sings about qualities of himself or another person but without heterosexual involvement. The Social Value category is for songs whose dominant theme is concerned with aspects of society. Songs are classified as Religious if they concern a deity or extol spiritual values. Nostalgic songs have some aspect of the past as their theme. Songs categorized as Novelty are instrumental, or nonsensical in their lyrics.

\section{Heterosexual Songs}

A thematic analysis of the top fifty songs in each genre reveals that the Heterosexual theme dominates all three types of music. Country songs are concerned with this theme in 82 per cent of the Iyrics (Table II). Soul and Easy Listening 
songs have 66 per cent and 60 per cent respectively. A total of 69 per cent of all the songs are devoted to the Heterosexual theme. Since one hundred and five of the one hundred and fifty-one songs are devoted to the Heterosexual theme, this theme is divided into two sub-categories. If the lyrics depict a happy relationship, the song is coded as Love Lauded. If the relationship portrayed is unhappy in nature, it is coded as Love Lamented. Relationships which are equally happy and unhappy, if any, are coded as Balanced.

\section{TABLE II}

ANALYSIS OF THEMES BY TYPE OF MUSIC

\begin{tabular}{|c|c|c|c|c|c|c|c|c|}
\hline Theme & & $\begin{array}{l}\text { asy } \\
\text { tening }\end{array}$ & & oul & & $\begin{array}{l}\text { untry- } \\
\text { stern }\end{array}$ & & tal \\
\hline Heterosexual & 30 & $(60 \%)$ & 33 & $(66 \%)$ & 42 & $(82 \%)$ & 105 & $(69 \%)$ \\
\hline Personal & 13 & $(26 \%)$ & 5 & $(10 \%)$ & 5 & $(10 \%)$ & 23 & $(15 \%)$ \\
\hline Social Values & 0 & $(0 \%)$ & 5 & $(10 \%)$ & 2 & $(4 \%)$ & 7 & $(5 \%)$ \\
\hline Nostalgia & 3 & $(6 \%)$ & 0 & $(0 \%)$ & 1 & $(2 \%)$ & 4 & $(3 \%)$ \\
\hline Religious & 1 & $(2 \%)$ & 2 & $(4 \%)$ & 1 & $(2 \%)$ & 4 & $(3 \%)$ \\
\hline Novelty & 3 & $(6 \%)$ & 5 & $(10 \%)$ & 0 & $(0 \%)$ & 8 & $(5 \%)$ \\
\hline Total & 50 & $(100 \%)$ & 50 & $(100 \%)$ & 51 & $(100 \%)$ & 151 & $(100 \%)$ \\
\hline
\end{tabular}

In the Easy Listening category, twenty-three of the Heterosexual songs are sung by males, 77 per cent of this category. Of these twenty-three, 52 per cent belong in the Love-Lauded category, 48 per cent in the Love-Lamented category (Table III). 
TABLE III

ANALYSIS OF LOVE RELATIONSHIP BY GENDER AND TYPE OF MUSIC

\begin{tabular}{|c|c|c|c|c|c|c|c|c|}
\hline \multicolumn{9}{|c|}{ Males } \\
\hline Relationship & \multicolumn{2}{|c|}{$\begin{array}{l}\text { Easy } \\
\text { Liștening }\end{array}$} & \multicolumn{2}{|c|}{ Soul } & \multicolumn{2}{|c|}{$\begin{array}{l}\text { Country- } \\
\text { Western }\end{array}$} & \multicolumn{2}{|c|}{ Total } \\
\hline Love Lauded & 12 & $(52 \%)$ & 19 & $(73 \%)$ & 16 & $(67 \%)$ & 47 & $(64 \%)$ \\
\hline Love Lamented & 11 & $(48 \%)$ & 7 & $(27 \%)$ & 8 & $(33 \%)$ & 26 & $(36 \%)$ \\
\hline Balanced & 0 & $(0 \%)$ & 0 & $(0 \%)$ & 0 & $(0 \%)$ & 0 & $(0 \%)$ \\
\hline Subtotal & 23 & $(100 \%)$ & 26 & $(100 \%)$ & 24 & $(100 \%)$ & 73 & $(100 \%)$ \\
\hline \multicolumn{9}{|c|}{ Females } \\
\hline Relationship & \multicolumn{2}{|c|}{$\begin{array}{c}\text { Easy } \\
\text { Listening }\end{array}$} & \multicolumn{2}{|c|}{ Soul } & \multicolumn{2}{|c|}{$\begin{array}{l}\text { Country- } \\
\text { Western }\end{array}$} & \multicolumn{2}{|c|}{ Total } \\
\hline Love Lauded & 3 & $(43 \%)$ & 3 & $(43 \%)$ & 6 & $(33 \%)$ & 12 & $(37.5 \%)$ \\
\hline Love Lamented & 4 & $(57 \%)$ & 4 & $(57 \%)$ & 12 & $(67 \%)$ & 20 & $(62.5 \%)$ \\
\hline Balanced & 0 & $(0 \%)$ & 0 & $(0 \%)$ & 0 & $(0 \%)$ & 0 & $(0 \%)$ \\
\hline Subtotal & 7 & $(100 \%)$ & 7 & $(100 \%)$ & 18 & $(100 \%)$ & 32 & $(100 \%)$ \\
\hline Total & \multicolumn{2}{|c|}{30} & \multicolumn{2}{|c|}{33} & \multicolumn{2}{|l|}{42} & \multicolumn{2}{|l|}{105} \\
\hline
\end{tabular}

One of the most popular in the category of Easy Listening Heterosexual songs lauds love in a traditional manner. "And I Love You So" contains such Iyrics as "And I love you so/ The people ask me how/ How I've lived till now/ I tell them I don't know/ I guess they understand/ How lonely life has been/ But life began again/ The day you took my hand." In contrast, another lyric lauds "My love oh wo my love/ Only my love holds the other key to me/ oh/ My love oh, my love/ 
Only my love does it good to me." A male performer in a song entitled "In the Midnight Hour" promises "I'm gonna wait till the midnight hour/ When there's no one else around/ I'm gonna take you, girl, and hold you/ And do all the things I told you/ In the midnight hour, yes I am, oh yes I am," New values in the male-female relationship are indicated in a song called "Sweet Surrender." In these lyrics a male states, "Baby, I'm through runnin' it's true/ I'd be a fool to try to escape you/ Maybe I'm beat, but oh what a sweet surrender." In the one and only reference to the women's movement, the same singer capitulates with "You keep your rights/ I'Il take your nights . . . I'm givin' up myself to you/ But I didn't really lose at all." This may indicate acceptance of the women's movement as long as it does not interfere with love relationships.

Males in the Easy Listening Heterosexual category lament love in diverse ways. The one song in this genre describing divorce did so in non-vindictive terms. "Love has slipped away and left us only friends" perhaps states the middleclass point of view. The singer advises that "Now there's nothing left to do but go our separate ways/ And pick up all the pieces left behind us/ And maybe someday somewhere along the way/ Another love will find us." Even infidelity is lamented in a low key manner. In "How Can I Tell Her" the problem is that "Whenever I'm discouraged/ She knows just what to do/ But girl she doesn't know about you." Not all 
Easy-Listening males were so quietly unhappy. One laments, "She's giving me hell and if that's not enough/ She's breaking my heart nearly every day/ Not only in pieces but every way."

Two songs written about couples in love offer a contrast between the old and the young. The first has as its theme a couple whose love survives death. An old man is described as giving his wife a daisy a day during their lifetime. After her death "He feels all her love walkin' with him/ And he smiles at things she might say/ Then the old man walks up to the hilltop/ And gives her a daisy a day." The trauma of teenage romance is illustrated by "Jimmy Loves Mary-Ann." "Just seventeen, everything that you've seen, it's all there in your eyes/ So many years of a poor mama's tears and a Daddy's sweet Iies." "There's nobody home/ Mary-Ann's alone/ Almost fully grown and worldly wise." "Jimmy loves Mary-Ann/ Jimmy wants to be a man/ Jimmy loves Mary-Ann/ She thinks it's all right."

Female singers account for seven of the Easy Listening Heterosexual songs. As with males, these are divided between those that laud love and those that lament it. Forty-three per cent of the women laud love and fifty-seven per cent lament it. Women speak of loves who "light up their lives" in terms of the male's "sweet understanding." One female asserts, "I know you've had some bad luck with ladies before/ They drove you or you drove them crazy/ But more important is 
I know you're the one and I'm sure/ Lovin' you's the right thing to do." One song not only lauds love, but pregnancy as well. The singer states, "think I'm gonna have a son/ He'll be like him and me, as free as a dove/ Conceived in love/ Sun is gonna shine above." Interestingly, this was one of the few "cross-over" recordings which is popular in both Easy Listening and Country-Western genres, although its popularity is much greater in Easy Listening, where it ranks eleventh, than in Country-Western, where it is forty-fifth.

Unhappy women in the Easy Listening Heterosexual category lament love in a subtle manner. Love affairs are ended sedately with such lines as "We've seen how love can grow/ Now we'll see how it dies." Only one bitter f'emale castigates a rejecting male with "You gave away the things you loved and one of them was me" and concludes with "You're where you should be all the time and when you're not/ You're with some underworld spy or the wife/ of a close friend."

Over all, the Easy Listening Heterosexual songs are lowkey, subtle, complex, and diverse in their style. Affairs are ended, divorces decreed, and love is celebrated in euphemistic terms. The strident cries of Soul singers and the tears of Country-Western ones are absent.

Conversely, Soul songs are of a different order. Twentysix of the Heterosexual Soul songs are performed by males and seven by females. Of the twenty-six male songs, nineteen laud love and seven lament it, 73 per cent and 27 per cent of 
the male Sold Heterosexual category. Of these songs which laud love, five concern seduction. The most popular Soul song of 1973, "Let's Get It On" states that "You can't have to worry that it's wrong/ If the spirit moves you let me groove you good/ Let your love come down oh." Two others issue ultimatums such as "Give me all the things I need . . Come on girl it's time to get down, down babe." Another simply states, "Get it together or leave it alone/ If you don't want my loving I'Il be gone/ mm gone/ Get up off your high horse, girl." One male promised to "Fill your well, your hopes, your dreams/ Believe me girl you got everything." Infidelity is dealt with happily in "Me and Mrs. Jones," who are reputed to have "a thing going on/ we both know that it's wrong/ but it's much too strong/ to let it go now." In "Stoned Out of My Mind" infidelity is lamented with "When I found out you were a-lying/ Playing around and conniving/ Undesired tears I was crying." In "Leaving Me" rejection is concerned. "Girl, if you only knew what was going through my mind/ You'd stop fooling around and give me all your time." One male warned his partner, however, "For me to stay I've got to be me."

Soul female singers in the Heterosexual category basically lament love. Four of their seven songs are unhappy. These songs concern broken relationships. One woman cannot stand the rain because "he's not here with me." One masochistic female asserts, "It ain't no good till it hurts a little bit/ 
cause it hurts so good." While no songs are concerned specifically with divorce in this genre, one is devoted to ending a relationship. "I keep wondering what I'II do without you/ And I guess you must be wondering that same thing too/ So we go on together living a lie/ Because neither one of us wants to be the first to say goodbye" expresses similar values to those in the Easy-Listening song about divorce. Both are non-vindictive in orientation. Female Soul singers who laud love are as concerned with seduction as males. One lady states, "Friends who tell me wrong from right/ I'll ask to borrow their man some cold lonely night." Soul women singers are ambivalent toward their love objects, either wanting them desperately or caught in the difficultues of the "bittersweet" experience mentioned by Shaw.

Among Country-Western Heterosexual songs, 82 per cent of which are devoted to this theme, men in this genre laud love at a ratio of two to one. Further, unilike the other genres, males in the Love-Lamented category blame themselves rather than their partners for the unhappy relationship. Two of the songs in this genre were male/female duets. Duets do not occur in the other genres. One of the duets lauds love and the other laments it.

Songs sung by male Country-Western singers in the LoveLauded category are quite frequently erotic in theme. The songs rated one and two in the country genre are explicit in 
their lyrics. In "You 've Never Been This Far Before," such lyrics as "I don't know what I'm saying as my trembling fingers touch forbidding places . . ." carry a message which is actually infidelity rather than a loss of innocence. This is emphasized in the line "I don't know what made you tell him you don't love him anymore." The second rated Country-Western song, which is another "cross-over" to the Easy-Listening genre, where it ranked thirtieth is "Behind Closed Doors." In this song a male lauds the love relationship with the lines "And when we get behind closed doors/ Then she lets her hair hang down/ And she makes me glad I'm a man/ oh no one knows what goes on behind closed doors."

Other Country-Western males laud love with such statements as "Lovin' you performed a miracle/ I don't need no wings to fly/ I just took a trip to heaven/ I didn't even have to die." Another states graphically, "When I wake up early in the morning/ The first thing on my mind is loving you." One male proposes marriage in the song "Come Live With Me" with the concrete promise to "build a roof to shield your head/ with these hands I'll carve the wood for a baby bed." Marriage is lauded, at least indirectly, in three of the Country-Western songs sung by males. It is not mentioned by males in the other genres.

Unlike the other types of songs, Love-Lamented, Heterosexual Country-Western songs performed by males are concerned with the male's own actions in a troublesome love relationship. Thus 
one song says, "She's not feeling too well/ Cause I put her thru hell still she forces a smile/ She's got to be a saint/ Lord knows that I ain't." Another describes the situation as, "I don't blame her for leaving, Lord, she didn't want to go/ But she thinks I don't love her or need her anymore/ I've driven her into a world as hard and cold as ice/ With no one there to hold her when she cries." A further comment is, "Now once again I'm here to take advantage/ Though I don't deserve the arms I left alone."

Country-Western female singers are an unhappy lot. Twelve of their eighteen songs lament love. The third most popular Country-Western song, "Satin Sheets" finds a woman lamenting, "I've found another man who can give more than you can/ Though you've given me everything money can buy/ But your money can't hold me tight like he does on a long, long night/ You know you didn't keep me satisfied." Problems of divorce are viewed differently from those in the other genres. In "Rated $X$ " one female states, "If you've been a married woman/ And things didn't seem to work out/ Divorce is the key to bein' loose and free/ So you're gonna be talked about. . You can't have a male friend when you're a has-been of a woman/ You're rated X." Further complicating this status, she says, "And if you're rated $\mathrm{X} /$ You're some kind of goal every man might try to make. . . The women all look at you like you're bad/ And the men all hope you are." 
Another female simply laments, "I'll just keep fallin' in love/ Til I get it right."

Female Country-Western singers laud love relationships in several ways. Advice on keeping a man's love is given in "Love's the Answer." It is suggested to "touch him gently so he'll understand/ Be proud of him when you know he's done his best/ Let him know you think he's better than the rest." Another lauds the physical relationship by stating, "He reaches out his hand and without a word/As his fingers softly fall upon my face/ He lights the flame of desire and makes me want him." Another female subtly promises, "When the dreams that you've chased have all gotten away/ And you stand at the end of a long lonely day/ You will never be far from these arms of mine."

In general, Easy-Iistening males and females in the Heterosexual category address each other in more complex terms than they do in the other two genres. Males in this category are more critical of the love relationship than males in the other groups. Soul male singers, on the other hand, promise physical satisfaction and respond in the love relationship with enthusiastic abandon. Their main fear is rejection in the love relationship. Country-Western males differ from the males in other genres in their fearfulness and self-depreciation. They admit personal problems and blame themselves for difficulties in the love relationship. Country-Western males seem to be seeking a nurturing and 
stable female who can somehow ease the pain they feel in their lives.

Due to the smaller number of songs directed to and about men in the love relationship, it is difficult to assess female values. Easy-Listening female singers seem to seek emotional satisfaction on love relationships. Both EasyListening and Soul female singers view loss of a man's love as traumatic. Soul female singers are merely saddened by the downward course of love, not bitter or vindictive. They laud love by being sexually aggressive and frankly seductive. Country-Western female singers are most critical of love relationships. They express concern with male infidelity. This may reflect the high breakup rate of marriages in bluecollar occupational classes, but does not explain why this criticism is not present in Soul songs performed by females, who also deal with males in blue-collar occupations. Only one Country-Western female is seductive, and she assures the man in question that it is only because of the loss of a previous love. "The one I loved left me/ Ieft me lonely and cold and so weak/ And I need someone's arms to hold me/ Til I'm strong enough to get back on my feet." This is hardly calculated to stimulate male pride. Only one Country-Western female expresses the view that love had put her on "Top of the World."

It is possible that Country-Western men are facing a myriad of problems in a white-collar middle-class society. 
The uncertainty of their position may explain their pleading and self-effacing attitude. This very attitude appears to make them vulnerable to criticism from their female companions. There is no evidence of male pride in the love relationship which is present in the lyrics of Soul music.

\section{Personal}

other songs popular in 1973 have as their focal point relatives, friends, or personal statements about the singer. As evidenced by Table II, about 15 per cent of all the songs belong in the Personal category. This category contains the largest number of songs not falling into the Heterosexual category. The genre having the largest number in the Personal category is Easy Listening. One song portrayed a man named "Bad, Bad, Leroy Brown" who was described as "The baddest man in the whole damned town/ Badder than old King Kong/ And meaner than a junkyard dog." This gambler, fancy dresser, and fighter is also known to have a "32 gun in his pocket for fun/ He got a razor in his shoe." In contrast, a peaceful male was born again in the solitude of the Rocky Mountains. "Now he walks in quiet solitude the forests and the streams/ Seeking grace in every step he takes."

Females in this category described male musicians in two songs. One extols the virtue of solitude in "Peaceful." The personal problem of being half American Indian is articulated by one female, who asserts, "Half-breed, she's 
no good they warned/ Both sides were against me from the day I was born." The end result of this discrimination is "My Iife since then has been from man to man/ But I can't run away from what I am."

Soul songs in the Personal category are all concerned with males. "Superfly" depicts the virtues of the black super hero. "The man of the hour has an air of great power/ The dudes have envied him for so long." "I don't understand him but he's a hell of a man/ This cat of the slum had a mind, wasn't dumb." An anti-hero is described as "Harry Hippie lies asleep in the shade/ Iife don't bug him cause he thinks he got it made/ He never worries about nothing in particular." One male laments that "Nobody Knows You When You're Down and Out." A female describes her father as "Daddy wasn't no scholar naw/ No he didn't have a PhD/ huh but in my eyes and way down in my heart/ My daddy means the world to me."

Country-Western Personal songs focus on aspects of male life. Most articulate problems of men. A prisoner of war wonders if he is remembered at home; one man is depressed; a third, at loose ends and out of work, is hitchhiking to Mexico. Liquor is a problem for a fourth, who says to a female critic, "The Lord knows I'm drinkin' and runnin' around/ And He don't need your loud mouth informin' the town." One Personal song is sung by a female about a parent whose gender is not determined. In it she apologizes for having taken the parent for granted. 
In the Personal category, images of males differ from genre to genre. Country males differ from Soul males in their lack of braggadocio. Where Soul males are selfassured, Country-Western males are again apologetic. They report lack of job opportunities, drinking problems, and depression. Soul men brag of their cunning, strength, and independence. Easy-Listening males range from the extreme confidence of bad Leroy Brown to the gentleness of the man in "Rocky Mountain High." One man's song about his brother is characteristic of the poetic form of this genre. "Oh Daniel my brother you are older than me/ Do you still feel the pain of the scars that won't heal/ Your eyes have died but you see more than I/ Daniel you're a star in the face of the sky." This genre also contains the only Personal songs about females.

\section{Social Values}

Social-Value songs have as their themes either aspects of the environment or statements about social conflict and social values. The absence of any songs belonging in this category in the Easy-Listening group is of special interest. Soul lyrics are devoted to this theme 10 per cent of the time. Country-Western Iyrics deal with Social Values in 4 per cent of the songs. The absence of Social-Value songs in Easy Listening may indicate middle-class acceptance of the status quo or a lack of perception of problems which do exist in 
society. The year 1973 was the first since the end of the Viet Nam War. The lack of protest and anti-war songs in this genre may be due to a national desire to forget as quickly as possible.

Soul songs in the Social-Values category are of two themes. Of all genres, they are the only ones concerned with racial brotherhood. They also lash out at conditions in the ghetto. Two songs adrocating brotherhood contain such lines as "People all over the world/ Join hands start a love train, love train" and "No matter what color/ Um you are still my brother/ Everybody wants to live together/ Why can't we live together?"

The Soul songs about environmental problems have great impact. The twentieth most popular song in this genre is entitled "The World Is a Ghetto." The world is described as "Walking down the street smoggy eyed/ Looking at the sky starry eyed/ Searching for a place weary eyed/ Crying in the night teary eyed/ Don't you know that it's true/ That for me and for you/ The world is a ghetto." The thirteenth most popular Soul song describes the same problem. "Kids dodging cars for recreation/ only adds to the much frustration/ Break-ins, folks coming home and finding all their possessions gone/ It's an everyday thing in the ghetto." of special note, both because of its perception of environmental problems and its images of the black male is "Are You Man Enough?" While the psychological implications of 
these lyrics are beyond the scope of this paper, they point to what sociologists have labeled "oppression psychosis" (2, p. 368). This song contains such lyrics as "Are you man enough/ big and bad enough/ Are you gonna let them shoot you down/ When the eagle flies and your brother cries/ Are you gonna be around?" The problems of minority relations are mentioned as "There's no pretending it goes away/ With every step that you take you pay your dues/ And I ain't lying/ You got to struggle to see the light/ Cause someone's looking to steal your right to choose/ And they don't stop trying." This song promotes a philosophy of "The strong survive/ They stay alive/ They always do/ But that they never teach you in school." Those who believe that the black movement is quiet and that discontent has been quelled need only listen to black popular lyrics. They articulate the problem in a colorful way and imply that environmental problems are at least part of the difficulty.

Country-Western singers have little to say on the subject of social values. Only two songs, both sung by and about males, are included in this category. One is ostensibly addressed to Henry Ford and humorously comments on the expense of maintaining an automobile in United States society. "But that four wheel buggy is dollarin' me to death/ For gas and oil and fluids and grease/ and wires and tires and antifreeze." This expense is necessary, however, as he comments that "we measure a man's success/ By the kind of automobile 
that he can buy." The precarious position of the workingclass male, as formulated in other studies of Country-Western music, is illustrated by "Rednecks, White Socks and Blue Ribbon Beer." The term "redneck" has come to denote a person who holds reactionary sentiments. A realization that one is not a member of the dominant social group, or that his work is somehow demeaning, can trigger the sense of male identity evident in the lines, "No we don't fit in with that white collar crowd/ We're a little too rowdy and little too loud/ But there's no place that I'd rather be than right here/ With my redneck, white socks and blue ribbon beer."

\section{Nostalgia}

The Nostalgia category includes songs about the "good old days" and the singer's childhood. The absence of songs dealing with the Nostalgia theme in the Soul genre is of special interest. It is possible that producers and consumers of Soul music, largely the black subculture, do not feel nostalgic about any of their past, with good reason. Evidently the "good old days" for this group never existed. Since their consumption of Social-Value songs is higher than any other group, it is possible that they are looking to the future rather than at the past. The concern is focused on racial brotherhood and environmental problems which may be changed.

The largest percentage of Nostalgia songs, 6 per cent of the genre, occurs in the Easy-Listening group. This is 
possibly due to middle-class concern with maintaining the status quo and middle-class concern with the past. Urban change is mentioned in one song. "They're tearin' down the street where I grew up/ Like pourin' brandy in a Dixie Cup/ They're paving concrete on a part of me/ No trial for killin' of a memory." A female sang of a past time "When I was young I listened to the radio/ Waitin' for my favorite songs/ And when they played I'd sing along/ It made me smile." This tenth most popular song in its genre is not only nostalgic, but it may be a clue to the reason that popular songs are still a viable medium of expression today. The one and only Country-Western song in this category is concerned with "0ld Dogs, Children and Watermelon Wine" as being the only worthwhile things left in the world.

\section{Religious}

In a time of concern about religious values and publicity of the "Jesus Movement" in the popular media, there is an absence of religious songs among all three genres. In the Soul group two songs occur, by the same performer, both focused on spiritual beliefs rather than a deity, in "Higher Ground" and "Superstition." One Religious song occurs in the Easy-Listening genre, in forty-ninth place. Extremely popular, seventh in its group, is the CountryWestern song "Why Me," which is directed to a particular deity, Jesus. It contains the self-effacing attitude 
present in other Country-Western lyrics. It begins, "Why me, Lord? What have I ever done to deserve even one of the pleasures I've known?"

\section{Novelty}

The Novelty category contains instrumentals and nonsensical songs of various kinds. There are no Novelty songs in the Country-Western group. Most of the CountryWestern songs appear to be serious in lyric content, and it is possible that humorous songs are not well received.

The Soul genre contains five Novelty songs, 10 per cent of the genre total. They range from the nonsensical "Will It Go Round in Circles" and "Funky Worm" to semi-instrumentals with shouted phrases on the part of the musicians.

Six per cent of the Easy-Listening songs are Novelty songs. Two of these are instrumental themes from films. Another is "Sing," which has been popularized by the children's educational program "Sesame Street."

As previously stated, Heterosexual songs comprise the largest category of the top singles of 1973 in every genre. They account for 69 per cent of the songs in the sample. It is possible that these songs directed at the male-female relationship contain images of masculine and feminine behavior which are reinforced by the culture. They also reflect the national preoccupation with the love-sex relationship. Personal songs comprise the second largest 
category, with Social Values and Novelty songs tied for an equal number of songs. A small percentage of the songs have the themes of Religious and Nostalgia.

The way in which masculine and feminine roles are portrayed in popular lyrics will be subjected to further analysis. 


\section{CHAPTER BIBIIOGRAPHY}

1. Braudy, Susan, "The Queen of Country Music: 'Stand By Your Man, " Ms, I, No. 9 (March, 1973), 27-31.

2. Horton, Paul B. and Chester S. Hunt, Sociology, New York, McGraw Hill Book Company, 1972.

3. Newsweek, June 18, 1973, pp. 65-72. 


\section{CHAPTER IV}

\section{ANALYSES OF ADDRESS, PRESENTATION, AND SEX ROLES}

In this chapter those songs previously designated Heterosexual are subjected to further analyses to determine the images which popular Iyrics present of men and women.

\section{Analysis of Address}

First the Heterosexual songs are analyzed to determine which songs are directed to women and which songs are directed to men. Songs sung by male performers and directed to a love object, presumed to be female, are categorized as songs directed to women. Songs sung about women by male performers are also included in these songs about women. Songs performed by female singers and directed to a love object, presumed to be male, are categorized as songs directed to men. Songs about a man or men are included in the male category. Heterosexual songs about couples, including those which are duets, are excluded. A total of ninety-four songs are available for analysis (Table IV). Seventy-one per cent of the songs are directed to or about women. Twenty-nine per cent of the songs are directed to or about men. As shown in Table IV, the Easy-Iistening genre has the highest percentage of songs 
about women. Country-Western songs have the highest percentage of songs about men. However, only twenty-seven of the ninetyfour songs are directed to or are about men. The small number of songs about men make it difficult to determine their presentation accurately. On the other hand, sixtyseven of the songs are about women, presenting a more accurate assessment of their presentation. Since most of the performers are male, it is obvious that these love songs will be about women. To determine the way in which men present women in song and the way in which women present men, these songs are subjected to Kaplan and Goldsen's criteria for evaluating a symbol (1, p. 75).

\section{TABLE IV}

ANALYSIS OF ADDRESS BY TYPE OF MUSIC

\begin{tabular}{|c|c|c|c|c|c|c|c|c|}
\hline \multirow{2}{*}{$\begin{array}{l}\text { Address of Song } \\
\text { To a Female }\end{array}$} & \multicolumn{2}{|c|}{\begin{tabular}{c|} 
Easy \\
Listening \\
\end{tabular}} & \multicolumn{2}{|c|}{ Soul } & \multicolumn{2}{|c|}{$\begin{array}{l}\text { Country- } \\
\text { Western }\end{array}$} & \multicolumn{2}{|c|}{ Total } \\
\hline & 15 & $(55 \%)$ & 20 & $(61 \%)$ & 14 & $(40 \%)$ & 49 & $(52 \%)$ \\
\hline About a Female & 6 & $(22 \%)$ & 5 & $(15 \%)$ & 7 & $(21 \%)$ & 18 & $(19 \%)$ \\
\hline To a Male & 5 & $(19 \%)$ & 5 & $(15 \%)$ & 7 & $(21 \%)$ & 17 & (18\%) \\
\hline About a Male & 1 & $(4 \%)$ & 3 & $(9 \%)$ & 6 & $(18 \%)$ & 10 & $(11 \%)$ \\
\hline rotal & 27 & $(100 \%)$ & 33 & $(100 \%)$ & 34 & $100 \%$ & 94 & $100 \%)$ \\
\hline
\end{tabular}


Analysis of the Direction of Presentation

As stated in Chapter II, Kaplan and Goldsen establish criteria for clarifying a symbol, in this case a male or a female, into the following categories: positive, positive with qualification, negative, negative with qualification, balanced, and no direction of presentation (1, p. 75). Since those songs which do not deal with either a male or a female are excluded from this study, the category "no direction" is eliminated. In all cases, the point of view is that of the artist performing the song. If the singer is a male and the song contains lyrics which describe a faultiess female, the song is rated as a positive presentation of a female subject. Although there are presentations of the singer himself in most of the songs, for purposes of analysis the songs are dichotomized into songs about women and songs about men.

As Table $\mathrm{V}$ indicates, women are presented positively by a large percentage in every genre. Men are positively presented in 50 per cent of the songs in the Easy-Listening and Soul genres. Only in the Country-Western genre are men presented negatively. The presentations will be discussed by genre to provide examples of positive and negative presentations.

Easy Listening.--In the Easy-Listening genre, women are presented positively with qualification in ten songs. "Diamond Girl" is an example of a positive presentation by a male. She is described as "like a precious stone/ Part 
of earth where heaven has rained on. . Day or night time - . like a shinin' star." One of the most popular Iyrics. number five in this genre, has as its theme a woman who deserts her husband and children to dance in burlesque. This is one of the two female occupations mentioned in the entire sample.

\section{TABLE V}

ANALYSIS OF THE DIRECTION OF PRESENTATION

BY GENDER AND TYPE OF MUSIC

\begin{tabular}{|c|c|c|c|c|}
\hline \multicolumn{5}{|c|}{ Females } \\
\hline & $\begin{array}{c}\text { Easy } \\
\text { Listening }\end{array}$ & Soul & $\begin{array}{l}\text { Country- } \\
\text { Western }\end{array}$ & Total \\
\hline Positive & $10(48 \%)$ & $9(36 \%)$ & $13(62 \%)$ & $32(48 \%)$ \\
\hline $\begin{array}{l}\text { Positive with } \\
\text { Qualification }\end{array}$ & $4(19 \%)$ & $10(40 \%)$ & $5(23 \%)$ & $19(28 \%)$ \\
\hline Negative & $1 \quad(5 \%)$ & $0 \quad(0 \%)$ & $1 \quad(5 \%)$ & $2(3 \%)$ \\
\hline $\begin{array}{l}\text { Negative with } \\
\text { Qualification }\end{array}$ & $6(29 \%)$ & $6(24 \%)$ & $2(10 \%)$ & $14(21 \%)$ \\
\hline Balanced & $0 \quad(0 \%)$ & $0 \quad(0 \%)$ & $0 \quad(0 \%)$ & $0 \quad(0 \%)$ \\
\hline No Direction & $N=21$ & $\mathrm{~N}=25$ & $\begin{array}{c}--- \\
N=21 \\
\end{array}$ & $N=67$ \\
\hline & $\begin{array}{c}\text { Easy } \\
\text { Iustening }\end{array}$ & $\begin{array}{c}\text { Males } \\
\text { Soul } \\
\end{array}$ & $\begin{array}{l}\text { Country- } \\
\text { Western }\end{array}$ & Total \\
\hline Positive & $2(33 \%)$ & $3(38 \%)$ & $3(23 \%)$ & $8(30 \%)$ \\
\hline $\begin{array}{l}\text { Positive with } \\
\text { Qualification }\end{array}$ & $1(17 \%)$ & $1(13 \%)$ & $2(16 \%)$ & $4(15 \%)$ \\
\hline Negative & $2(33 \%)$ & $0 \quad(0 \%)$ & $5(39 \%)$ & $7(26 \%)$ \\
\hline $\begin{array}{l}\text { Negative with } \\
\text { Qualification }\end{array}$ & $1(17 \%)$ & $4(50 \%)$ & $3(23 \%)$ & $8(30 \%)$ \\
\hline Balanced & $0 \quad(0 \%)$ & $0 \quad(0 \%)$ & $0 \quad(0 \%)$ & $0 \quad(0 \%)$ \\
\hline No Direction & $N=6$ & $\mathrm{~N}=8$ & $\begin{array}{l}\cdots- \\
N=13\end{array}$ & $N=27$ \\
\hline
\end{tabular}


The woman is described as "'struttin' in her birthday clothes" much to the chagrin of her husband. "Say Has Anyone Seen My Sweet Gypsy Rose?" somehow maintains an aura of lightheartedness in spite of its negative female image. Another female, referred to as "Bad Dog Baby;" is told to "keep your hands to yourself/ I'm strictly out of bounds." Another negative presentation is of an inconsistent female. "One minute you're full of life and the next you're sad/ one minute you"re marvelous and the next you're bad," she is told. While most of the songs are complimentary to women, those which are not are especially demeaning. Between Gypsy Rose's nudity and Bad Dog Baby's roving hands, women appear in an unflattering light.

Men in the Easy-Iistening lyrics are presented positively in one half of the songs women sing about them. "You light up my life," one woman says to her beloved, "like sunshine in the morning/ You make me believe anything is possible." Another woman states, "In the morning when I rise, you bring a tear of joy to my eyes and tell me/ Everything is gonna be all right." Men are presented negatively without qualification in one third of the songs about them. An extremely negative song portrays male vanity. "You walked into the party like you were walking onto a yacht/ Your hat strategically dipped below one eye/ Your scarf it was apricot/ You had one eye in the mirror as you watched yourself gavotte/ And all the girls dreamed that they'd be your partner. . . and you're so vain, 
you probably think this song is about you." This song is interesting not only for its male image but for its illustration of an upper middle-class lifestyle. The lyric pattern also uses a more complex vocabulary not found in the other musical genres.

Soul.--Women in Soul songs are presented positively, without reservation, in nine songs. In ten songs they are presented positively with some qualification. There are no completely negative songs about women in the Soul genre. In "Ain't No Woman (Like the one I Got)" a woman is described as making "the birds sing in harmony/ Each drop of rain is glad it found her/ Heaven must have made her just for me." This man further states his devotion because of two marvelous attributes she possesses. One is "to make her happy didn't take a lot" and the other is "Cause my word she'll obey." Women who are presented negatively with qualification are told that they are loved but their independence and hesitancy in the love relationship are irritating to men. "You ain"t doin' nothin' but jivin'/ We've got a very serious problem here," one is told. Reticence in the love relationship evokes a very negative response on the part of Soul male singers. Women Soul singers present men positively 50 per cent of the time. "You can make my life by breathing in the air/ Letting you know, child, just how much I care," one woman says. None of the Soul songs present men in a totally negative manner. In an example of a qualified negative 
presentation, a woman relates the problem of the black male in urban society. "I. A. is just too much for him/ So he's leavin' the life we've come to know," she states. His destination is Georgia and "goin" back to the simpler place and time." She plans to accompany him because "I'd rather live without him in mine." This song speaks of some of the reasons and emotions which may mark the black migration back to the South.

Country-Western.--Women in the Country-Western genre are presented very positively. They are described in glowing terms for their supportive nature. "She gives me strength to face tomorrow/ She comforts me in times of sorrow" is an apt description. In "Super Kind of Woman" a female is portrayed positively for the quality of her nature. "She came to me so gentle and so sweet/ Easy loving swept me off my feet." Another is praised because "She's always a lady just like a lady should be/ But when we turn off the lights, she's still a baby to me."

Negative presentations of women usually concern their inability to sustain a peaceful relationship. One male states, "Tho I"ve tried and tried to keep her tied/ and satisfied until she really needs me/ When that certain look comes on her face/ I can't replace it and she leaves me." Another male sings in exasperation, "Wanting you, I know, I'm throwing good love after bad/ But I'Il admit the worst of you is still the best I've had." 
Males in this genre are presented negatively by female singers 62 per cent of the time. They are soundly criticized by women in song. They are also praised in a few songs. "Each night is filled with such good loving/ He always seems to know what I'm thinking of/ Though we don't belong to each other, we feel no shame/ 'Cause everything we do is filled with love" describes one man's qualities. A rejected female describes a male's qualities with some reservations. "He didn't cuss with every breath/ He had a soothing Southern Drawl/ And made me feel like a lady through it all/ But he just caught the Jamestown Ferry. . He said that gone was all he'd ever be." Criticism is even more vocal in "Superman," which, unlike the title's implication, is about a man critical of the female singer. "And there you go pickin' on me again/ Pushin' me to the very end/ Telling me to move another mountain/ Well just cause you can walk on water/That ain't no sign I can/ You know your mama should have named you superman." Female Country-Western singers present a view of the white working-class male which is generally unfavorable. Perhaps his articulation of his own problems in song creates such a negative image that females echo his doubts about himself.

In general, women are presented positively in popular lyrics. Those songs in which women are presented negatively tend to be demeaning to women. Women are much more often presented as unfaithful and inconsistent than men are, in 
spite of the fact that songs about men are not too favorable. Easy-Listening songs are more complex and diverse in their presentation of women and also most critical of women. Soul singers present women positively, with some qualifications. The black male finds fault with women less frequently than the male in the Easy-Listening group. On the other hand, males in the Country-Western genre praise women for their supportive nature. Conversely, women in Country-Western Iyrics present men most negatively.

A partial explanation for this phenomenon may be found in Mirra Komarovsky's study of white working-class marriages. Komarovsky found that when women in such marriages were unhappy, they did not communicate this fact to their husbands (2, pp. 148-177). Husbands in her sample did not accurately perceive this discontent, since little communication existed in the marital relationship. This same factor may be operating in the relationships portrayed in Country-Western songs. Men are simply not sensitive to women's discontent. This may explain the positive presentation of women and the negative presentation of men in this genre. Jens Iund (4) in his study of Country-Western lyrics also found that men frequently articulate problems of drinking and infidelity in songs about themselves. The male role for them creates pressures from which they feel they must escape. It appears that men in Country-Western lyrics seek a nurturing, strong woman to ease some of the pain they feel in their lives, and find only rejection instead. 
Analysis of Sex Roles

Two analyses are performed to assess the way in which the one hundred and five Heterosexual songs portray feminine and masculine roles. Six traits associated with the feminine and masculine stereotypes were selected for analysis. The definition of these traits appears in the Appendix.

Each song in this group is analyzed to determine if the female portrayed in the song conforms to the feminine stereotype. Figures are given for each trait showing the percentage of songs in which the female conforms to the trait, or she does not conform to the trait, or the trait is not present in the song. As previously stated, the feminine traits subject to analysis are supportive, inconsistent, submissive, dependent, hesitant, and beautiful.

The same group of songs is then analyzed to assess the extent to which the male conforms to the masculine stereotype. Percentages are given for males conforming, or males not conforming, or the trait being absent in the song. The masculine traits subject to analysis are aggressive, independent, demanding, consistent, active, and confident.

The portrayal of the male or female is considered conforming if the person is portrayed in the song as behaving in accordance with the trait, e.g., an aggressive male. If the portrayal is of an opposite trait, e.g., a passive male, the song is coded as not conforming. If no evidence of the 
trait or its opposite is present in the song, it is coded as lacking the trait.

\section{Female Sex Role Stereotyping}

Table VI presents the results of the analysis of conformity to the feminine stereotype. Women are presented as supportive and submissive in well over one third of the songs. The trait with which women most frequently conform is the "supportive" image. Females are portrayed as supportive in 41 per cent of the songs. Men in popular Iyrics describe women as simply making them "feel better." Women are presented as submissive in 37.5 per cent of the songs.

\section{TABLE VI}

ANALYSIS OF CONFORMITY TO SEX ROLE STEREOTYPE TRAITS IN FEMALES

\begin{tabular}{l|c|c|c}
\hline Trait & $\begin{array}{c}\text { Per Cent } \\
\text { Conforming }\end{array}$ & $\begin{array}{c}\text { Per cent Not } \\
\text { Conforming }\end{array}$ & $\begin{array}{c}\text { Per Cent Not } \\
\text { Mentioned in Song }\end{array}$ \\
\hline Supportive & 41.35 & 31.73 & 26.92 \\
Inconsistent & 27.88 & 19.23 & 53.37 \\
Submissive & 37.50 & 31.73 & 30.77 \\
Dependent & 28.94 & 44.23 & 26.83 \\
Hesitant & 24.04 & 32.69 & 43.27 \\
Beautiful & 23.08 & 15.38 & 61.54 \\
\hline
\end{tabular}

In over one fourth of the songs women conform to the inconsistent image. Women are described as beautiful in only 23 
per cent of the lyrics. In the traits of hesitant and dependent, women do not conform to the stereotypical image. Women appear in lyrics as more independent than dependent and more assertive than hesitant. It must be remembered that in love songs women are frequently portrayed as rejecting a lover. This accounts for their lack of conformity to the dependent image. The rejection of a lover or the ending of a relationship is considered an independent act for purposes of analysis.

In general, four of the six traits show more women conforming to the stereotype than not conforming (Table VI). Two traits revealed women behaving in a manner opposite to the stereotypical image. One trait is dependent. The other is hesitant. The percentages conforming and not conforming are very similar. Consistency of behavior is not mentioned in over half of the songs. Popular songs frequently have the present as a setting. Therefore, consistency, or lack of it, in female behavior is not mentioned.

The fact that there is not wider support for the feminine stereotype in these lyrics is caused, in part, by the differences among genres. Traits which are supported in one genre are not supported in another. This causes averages to be lower when the stereotypical traits are combined.

These differences are illustrated in Table VII which gives a breakdown of the traits. Differences among genres then become apparent. For example, the trait "supportive" 
TABLE VII

A COMPARISON OF FEMALE STEREOTYPES IN THREE GENRES OF MUSIC

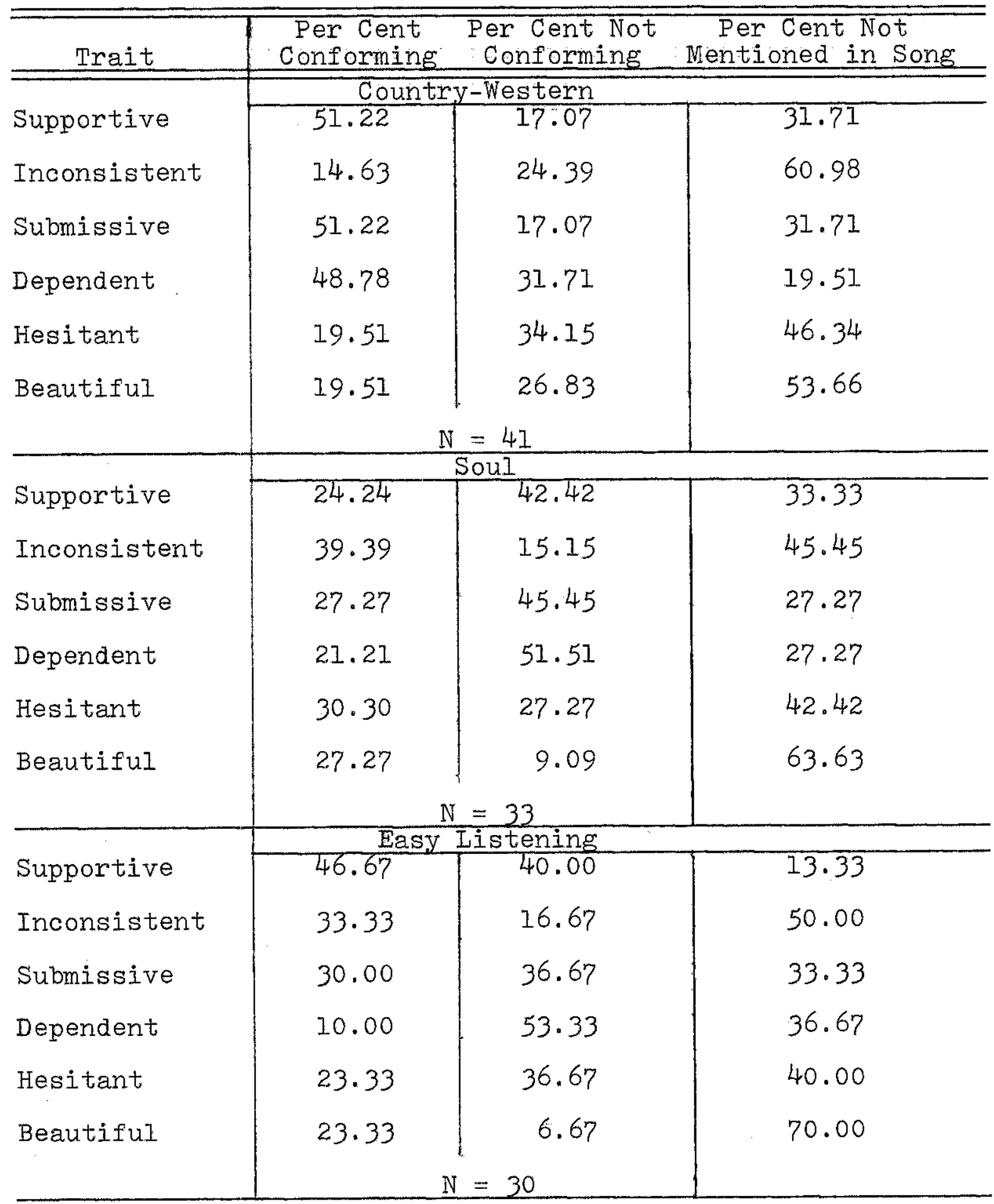


produces conformity in the Country-Western genre but not in the Soul genre. In the Easy-Iistening group, there is no clear-cut conformity to this trait. In this genre, 47 per cent conform to the trait while 40 per cent do not. Each genre, therefore, presents special traits. These will be analyzed in more detail.

Country-Western.--Women in Country-Western lyrics conform to the feminine stereotype in the areas of supportiveness, submissiveness, and dependency. Over half of the songs portray women in the submissive and supportive roles. Women in Country-Western lyrics do not conform to the stereotype in the areas of hesitancy, inconsistency, or beauty. A portrait emerges of a woman who does not hesitate to commit herself, and, once she does, her commitment is consistent. She is also presented with some flaws, as the beautiful stereotype is not supported.

Country-Western woman as supportive is pictured in "A Shoulder to Cry on" as "You seem to have a way with lonely people/ And you always were my greatest helping hand." In the second most popular Country-Western song for 1973, a supportive woman is described as being "never far away or too tired to say I want you." This must be the ultimate in supportiveness. Submissiveness is exemplified in "I'm out late every night doin' things that ain't right and she'11 cry for me/ And she'll never complain, she keep hiding the pain." Dependency is defined as being dependent on, 
controlled by, or greatly influenced by another. As such, "When her heart breaks the tears won't stop no matter how she tries/ And she needs someone to hold her when she cries" is an example. Hesitancy is not supported because lyrics such as these portray an assertive female. "Keep me in mind cause I'II never stop loving you/ And as long as I live/ I'll have love to give." Female traits such as submission and a stoicism in the face of disaster are reinforced in CountryWestern Iyrics. These lyrics express more the wishes of the male performers than the traits of working-class women. Soul.--Turning to the portrayal of women in Soul music, a different composite of traits emerges. This difference, in fact, accounts for the lower averages of adherence to the feminine stereotype in the total sample. Women in Soul Iyrics conform to the traits of inconsistent, hesitant, and beautiful, in that order. They do not conform to the stereotypical traits of supportiveness, submissiveness, and dependency. Inconsistency in the female in Soul songs is exemplified by lyrics such as "I tried to realize you being with some other guy/ I don't know the reason why/ You ought to be with me until I die." Her hesitancy is portrayed by a male singer as "If this was anything else/ You'd make up your mind right away/. And it seems like to me you're tryin' to delay/Can't you see, can't you see/ I want to love you." Her beauty, while not mentioned in 63 per cent of the songs, is lauded with such lyrics as "Who's that lady, sexy lady, 
beautiful lady, real fine lady." Conversely, women in Soul lyrics are non-supportive, non-submissive and, most of all, independent. "I was just a back seat driver in a car of love/ Going wherever you take me," one male laments of a beloved who is obviously not dependent on him. "When I tried to talk to you/ You turned on the TV, yes you did/ And gave me aggravation," another male says of a non-submissive female. "You can't take me for granted and smile," another male says of a non-supportive mate.

While these feminine traits supported in Soul lyrics are exactly opposite to traits supported in Country-Western lyrics (Table IV), they tend to support the black stereotype in which the female is strong, dominant, and independent. At best, they reinforce ideas which black females may already have about their roles and do nothing to change role concepts for either gender.

Easy Listening.--Women in the Easy-Listening genre differ from the other two genres in their adherence to stereotypical traits. They are not exactly like women in Country-Western or Soul songs. Their strongest conformity is to the "supportive" trait in 46 per cent of the songs. Even so, they are portrayed as non-supportive in 40 per cent of these songs. They are also inconsistent in their behavior in 33 per cent of the songs sampled. Women in this genre are also portrayed as beautiful 23 per cent of the time. While these women are pictured as submissive 30 per cent of the 
time, they do not conform to this stereotypical trait 36 per cent of the time. The strongest non-conformity is to the "dependency" trait. Women in Easy-Iistening songs are portrayed as not conforming to the dependency stereotype in 53 per cent of the songs. These figures only serve to pinpoint the diversity of role portrayal in the EasyListening genre. Part of this complexity may be due to the different types of songs which make up the Easy-Listening group. Approximately half of the songs in this genre are performed by young artists in the rock style. The others are a hodge-podge of romantic ballads, movie themes, and songs bordering on the Country-Western style. The rock songs may portray newer values of the youth culture while the other songs reflect the taste of older listeners. Female supportiveness is exemplified by Perry Como in a romantic ballad as "And you love me too/ Your thoughts are just for me/ You set my spirit free/ I'm happy that you do." A rock song, "Don't Expect Me to Be Your Friend," presents a non-supportive view. "You always look so happy when I see you/ You smile that way, you take my hand and then/ You introduce me to you latest lover/That's when I feel the walls start crashin' in." Independence is portrayed as "A house, a home, a family and a man that loves her so/ Who'd believe she'd leave us to join a burlesque show." With songs like this, it is quite obvious that women in this category are not dependent. They do not conform to the 
hesitant stereotype 36 per cent of the time. Their hesitancy to commit themselves is not evident. Seventy per cent of the Easy-Listening songs do not mention physical or personality attributes at all. This is the largest omission of a trait in any genre. Evidently such qualities are even less important than in other genres. The pedestal on which women were placed in lyrics of earlier years seems to have crumbled completely.

In summation, the differences among genres portray conformity to different stereotypical traits. In each genre three of the six female traits are supported. Conformity to any one trait is not evident among the three genres, thereby lowering percentages in conformity in the total number of female traits assessed. This shows differences in female stereotypes among ethnic and social subcultures.

\section{Male Sex Role Stereotyping}

In general, the conformity to the male traits of aggressive, demanding, consistent, active, and confident is supported (Table VIII). Only the trait of independence is not supported. Males appear to be more dependent than independent. It must be remembered that in the heterosexual relationship men are more likely to be dependent on, influenced by, or controlled by women. They are apt to be dependent on women for emotional and physical fulfillment. For this reason, men appear as dependent slightly more often 
than independent. This is in contrast with the masculine stereotype in other areas of life such as in occupational roles.

\section{TABLE VIII}

A.NALYSIS OF CONFORMITY TO SEX ROLE STEREOTYPE TRAITS IN MALES

\begin{tabular}{l|c|c|c}
\hline \hline Trait & $\begin{array}{c}\text { Per Cent } \\
\text { Conforming }\end{array}$ & $\begin{array}{c}\text { Per Cent Not } \\
\text { Conforming }\end{array}$ & $\begin{array}{c}\text { Per Cent Not } \\
\text { Mentioned in Song }\end{array}$ \\
\hline Aggressive & 50.96 & 23.08 & 25.96 \\
Independent & 41.35 & 45.19 & 13.46 \\
Demanding & 37.50 & 29.81 & 32.69 \\
Consistent & 42.31 & 36.54 & 21.15 \\
Active & 43.27 & 10.58 & 46.15 \\
Confident & 52.88 & 33.65 & 13.46 \\
\hline
\end{tabular}

Conformity to only two traits exists in all three genres. Men conform to the aggressive and active stereotype in all three genres. As with women, there are differences in other traits supported among genres (Table IX).

Country-Western.--Men in the Country-Western group conform to the stereotypical traits of aggressive, consistent, and active. Two traits, demanding and confident, result in tied percentages. The tied percentage in the demanding trait is due to the fact that males in Country-Western songs are presented as pleading as well as demanding in equal numbers. 
TABLE IX

A COMPARISON OF MALE STEREOTYPES IN THREE GENRES OF MUSIC

\begin{tabular}{|c|c|c|c|}
\hline Trait & $\begin{array}{l}\text { Per Cent } \\
\text { Conforming }\end{array}$ & $\begin{array}{l}\text { Per Cent Not } \\
\text { Conforming }\end{array}$ & $\begin{array}{l}\text { Per cent Not } \\
\text { Mentioned in Song }\end{array}$ \\
\hline & \multicolumn{3}{|c|}{ Country-Western } \\
\hline Aggressive & 43.90 & 26.83 & 29.27 \\
\hline Independent & 29.27 & 48.78 & 21.95 \\
\hline Demanding & 31.71 & 31.71 & 36.59 \\
\hline Consistent & 43.90 & 29.27 & 26.83 \\
\hline Active & 41.46 & $7 \cdot 31$ & 51.22 \\
\hline \multirow[t]{2}{*}{ Confident } & 41.46 & 41.46 & 17.07 \\
\hline & \multicolumn{2}{|c|}{$N=41$} & \\
\hline & \multicolumn{2}{|c|}{ Soul } & \\
\hline Aggressive & 69.70 & 24.24 & 6.06 \\
\hline Independent & 54.55 & 42.42 & 3.03 \\
\hline Demanding & $51 \cdot 52$ & $33 \cdot 33$ & 15.15 \\
\hline Consistent & 45.45 & 36.36 & 18.18 \\
\hline Active & 42.42 & 12.12 & 45.45 \\
\hline \multirow[t]{2}{*}{ Confident } & 66.67 & 21.21 & 12.12 \\
\hline & \multicolumn{2}{|c|}{$N=33$} & \\
\hline \multirow[b]{2}{*}{ Aggressive } & \multicolumn{2}{|c|}{ Easy Iistening } & \\
\hline & 40.00 & 16.67 & 43.33 \\
\hline Independent & 43.33 & 43.33 & 13.33 \\
\hline Demanding & 30.00 & $23 \cdot 30$ & 46.67 \\
\hline Consistent & 36.67 & 46.60 & 16.67 \\
\hline Active & 46.67 & 13.33 & 40.00 \\
\hline \multirow[t]{2}{*}{ Confident } & 53.33 & 36.67 & 10.00 \\
\hline & \multicolumn{2}{|c|}{$N=30$} & \\
\hline
\end{tabular}


Their articulation of problems they face and their assumption of responsibility in unhappy love relationships result in a lack of conformity to the confident role. The one trait to which males do not conform is the independent stereotype in Country-Western Iyrics. Forty-eight per cent do not conform to this frequently mentioned male role expectation.

Aggression is defined as the forceful pursuit of one's goal. As such, men in Country-Western lyrics say "Come live with me and be my love/ Let our dreams combine/ Be mate to me/ Be fate to me/ Be mine." Consistency is evidenced by the male singer in the lines, "But time's just deepened my devotion/ I love you more and more every day." Activity is defined as a male engaged in an expenditure of energy. Specific activities are mentioned such as occupation, travel, or sports. One male describes his occupation in "Amanda." "The measure of people can't understand/ the pleasures of life in a hillbilly band/ I got my first guitar when I was fourteen/ I'm crowding thirty and still wearing jeans."

Men in Country-Western songs appear both demanding and pleading in equal numbers. While one says, "Oh woman of mine I'm giving you warning/ I like loving early in the morning, baby" another apologizes "I'm no knight in shining armor/ I'll never carry you away." Confidence is telling cupid to "just keep the door to love open/ I'll make her mine." Lack of confidence is manifested in "When you look in the mirror in total surprise/ At the hair on your shoulders/ And the age 
in your eyes." Both confidence and lack of it appear in equal numbers. Men in Country-Western lyrics appear more dependent than independent. The independent trait was the only Country-Western male stereotypical trait not supported in the analysis. Men report such problems as inconsistent women. "You tell me go, then call me back/ And then you set me free." His partner is obviously influencing and controlling his behavior. Another male says to a female, "When my head gets kinda tangled and my soul is lying there/ I reach over in the corner of my life and I find you waiting there." He is dependent on her for emotional support.

Men in Country-Western lyrics conform to the stereotypical traits of aggressive, consistent, and active in over 40 per cent of the songs. Men appear confident and unconfident in equal numbers, both over 40 per cent of the time. Men appear both demanding and undemanding in equal numbers. This trait was both supported and not supported in 30 per cent of the songs. The trait not supported at all was that of independent. In 48 per cent of the Country-Western songs, men did not conform to the trait of independence. The white working-class male, as portrayed in Country-Western lyrics, is vacillating in his male role. He is aggressive, yet dependent. Perhaps this accounts for some of his mistreatment of women as articulated in Country-Western lyrics. Soul.--Turning to the male in Soul lyrics, a very different picture emerges. Males in Soul lyrics conform to 
the masculine stereotype in every trait. In the areas of aggression and confidence males conform to the stereotype in over 60 per cent of the songs. In over 50 per cent, males in Soul Iyrics conform to the independent and demanding traits. They also conform to the consistent and active stereotypical traits over 40 per cent of the time.

Aggression is exemplified as "Come on, come on darlin' Stop Beatin' around the bush/ on gonna get it right on with you baby/ I want to get it on." It is further exemplified in such lyrics as "I'm the red ball express of lovin'/ Diesel powered straight to you/ I'm truckin' . . . " Demanding is a more overt trait. It denotes an authoritative command. "Cut out all this shukin" and jivin" girl/ It's time to get down, get down." Also "Sit right down and talk to me/ About how you ought to be, you ought to be with me" is an example of a demanding male. Both of these songs denote an authoritative request. Males are confident, too. "I've come up hard baby but now I'm cool/ I didn't make it, sugar, playin' by the rules/ I've come up hard, baby, but now I'm fine/ I'm checkin' trouble, sugar/ Movin' down the line." Independence is denoted by a male who says, "If you want me to stay I'II be around today/ To be available for you to see/ I'm about to go and then you'll know/ For me to stay I've got to be me." Such males are also consistent. One says, "It always ends up this way/ Me begging you everyday/ For a love I cannot have...." Activity is noted in such actions as 
taking a train back to Georgia because Los Angeles is too much of a problem.

The male in Soul lyrics displays the "rabid machismo" mentioned by Marion Meade in her article about degrading lyrics (5). Further, while the male stereotype presented in Soul lyrics differs from the males in the lyrics of other genres, it conforms to findings in Elliot Liebow's study of the urban black male. In Chapter $\mathrm{V}$ of Tally's Corner, entitled "Lovers and Exploiters," Liebow (3) states that the men he studied prefer to see themselves as exploiters and their women as exploited. Actually, Liebow says that lip service to this cultural ideal is more widespread than the actual practice of it. One of the worst sobriquets applied to the black urban male is "sucker," "patsy," or their equivalent. Toughness is a necessary facade before one's peers. Further, Liebow states that in a world where sexual conquest is one of the few ways to prove one's masculinity, the man who does not take advantage of this in his relationship with women is considered "much less a man" (3, p. 150). It seems that males in Soul lyrics conform to the lower-class black male stereotype in even greater numbers than black women conform to the lower-class black female stereotype. Soul lyrics, then, serve to reinforce black stereotyping for both sexes.

Easy Listening.--Males in the Easy-Listening group of songs emerge as confident, aggressive, and active. Over half 
conform to the confident stereotype. "Forty-six and 40 per cent respectively conform to the active and aggressive role. Further, 30 per cent conform to the "demanding male" stereotype. Forty-three per cent of the songs conform to the independent trait, while 43 per cent do not. The only male trait in this genre not supported is that of "consistent." Men in Easy-Listening lyrics appear as somewhat dependent and inconsistent in their behavior.

Aggression is typified by such lyrics as "In the midnight hour/ That's when my love comes down/ I'm gonna take you girl and hold you/ and do all the things I told you." Male confidence is exemplified by such lines as "But when they turn out the lights/ I know she 'Il be leavin' with me." Activity in this genre means such events as the following: "Well I hear you went up to Saratoga and your horse naturally won/ Then you flew your Lear jet up to Nova Scotia/ To see the total eclipse of the sun." A demanding male tells a female, "Told you once before and I won't tell you no more so/ Get down, get down, get down, You're a bad dog baby . . ." The phrase "get down" here has a connotation of "stay away." This phrase as frequently used in Soul lyrics evidently means to face the issue.

Males are pictured as independent in lines such as "Don't think that I won't go/ You watch me/ It isn't out of the question." But they are also portrayed in equal numbers as dependent in a case where a female's symbolic acceptance 
is crucial. "I'm really still in prison and my love holds the key/ A simple yellow ribbon's what I need/ To set me free. . . " Males also appear changeable in behavior in Easy Listening songs. Thus one female laments, "Must've been hard to tell me that you've given all you have to give/ I can understand your feelin' that way/ ev'rybody got their life to live." Where males are inconsistent in behavior, it is for rejection in the love relationship. As previously stated, this is a common theme in popular lyrics.

Males in the Easy-Iistening genre exhibit the diversity of this type of song in their conformity to the masculine stereotype. The traits of confident, active, aggressive, and demanding are supported in these lyrics. There is a tie in the "independence" category. The masculine trait "consistent" is not supported.

\section{Comparison of Males and Females}

Females differ among genres in their conformity to stereotypical feminine traits, while males differ less among genres in their conformity to masculine stereotypes. Males and females in Soul music differ in their images from males and females in the other two genres. Men in Soul lyrics exhibit most conformity to the masculine stereotype. Women in Soul lyrics exhibit least conformity to the feminine stereotype. However, both sexes conform to stereotypes of sex roles in lower-class urban black culture. Both are aggressive and independent. 
Women in Country-Western lyrics exhibit the greatest conformity to three stereotypical female traits. Males in Country-Western lyrics exhibit less conformity to the masculine stereotype than males in the other genres. This is due to the dependent roles which they assume. Males in working-class culture may have difficulties with the male role because of their inability to communicate with traditionally oriented wives. Perhaps popular Country-Western lyrics function to articulate in song that which men are too inhibited to mention in person. As such, Country-Western lyrics may have a useful social function for working-class men. However, they serve to reinforce female stereotypes of submission and support. These lyrics do not function to humanize and equalize male and female roles.

Both males and females appear as inconsistent in the Easy-Listening genre. MaIes conform to the masculine stereotype in every area but independence. Females in Easy Listening lyrics exhibit least conformity to the dependent female stereotype. There is a role reversal in this area. As previously stated, part of the problem in assessing songs in this genre is that they reflect more than one type of music. It is possible, however, that the independent female portrayed in this genre is the product of middle-class emphasis on education and autonomy. A well-educated woman with a middle-class occupation is most likely to be independent. Compared with the position of women in Soul 
and Country-Western lyrics, she does not necessarily have to depend on a man for monetary support.

Table $X$ illustrates differences between males and females. Men in popular lyrics are, in general, more likely to conform to the masculine stereotype than women are to conform to the feminine stereotype. This may indicate greater differences in female role expectations among subcultures. Expectations for the male role may be similar among subcultures.

TABLE X

A COMPARISON OF CONFORMITY TO STEREOTYPICAL TRAITS BY SEX

\begin{tabular}{l|c|l|c}
\hline Male & $\begin{array}{c}\text { Per Cent } \\
\text { Conforming }\end{array}$ & $\begin{array}{l}\text { Female } \\
\text { Traits }\end{array}$ & $\begin{array}{c}\text { Per Cent } \\
\text { Conforming }\end{array}$ \\
\hline Demanding & 37.50 & Supportive & 41.35 \\
Consistent & 42.31 & Inconsistent & 27.88 \\
Aggressive & 50.96 & Submissive & 37.50 \\
Independent & 41.35 & Dependent & 28.94 \\
Confident & 52.88 & Hesitant & 24.04 \\
Active & 43.27 & Beautiful & 23.08 \\
\hline
\end{tabular}




\section{CHAPTER BIBLIOGRAPHY}

1. Budd, Richard W., Robert K. Thorp, and Lewis Donohew, Content Analysis of Communications, New York, The Macmillan Company, 1967.

2. Komarovsky, Mirra, Blue-Collar Marriage, New York, Vintage Books, A Division of Randon House, 1967.

3. Liebow, Elliot, Tally's Corner: A Study of Negro Streetcorner Men, Boston, Little, Brown and Company, 1967 .

4. Lund, Jens, "Fundamentalism, Racism, and Political Reaction in Country Music," in The Sounds of Social Change, edited by R. Serge Denisoff and Richard A. Peterson, Chicago, Rand McNally and Co., 1972.

5. Meade, Marion, "The Degradation of Women," in Sounds of Social Change, edited by R. Serge Denisof and Richard A. Peterson, Chicago, Rand McNally and Co., 1972. 


\section{CHAPTER V}

\section{CONCLUSION}

This investigation has sought to suggest the lyric content of popular music to describe sex role imagery in American society. This was accomplished by subjecting a sample of songs from three different musical genres to a method of research called content analysis. In this method, communication content is analyzed by tabulating the frequency with which data occurs in previously selected categories. Inferences may then be drawn about various aspects of communication data.

The sample of songs selected for this study was based on Billboard magazine's list of the fifty most popular songs of 1973 in each of the following musical genres: Easy Listening, Soul, and Country-Western. Due to a tie in one genre, a total sample of one hundred fifty-one songs was obtained. Iyrics of the songs were obtained from regularly published song lyric magazines, sheet music, tapes, and records.

To determine the gender of performing artists, the Billboard list was consulted. The list contained names of artists and recording companies in addition to song titles. Published material and photographs of the artist were consulted to determine the gender of performers. It was 
found that 46 per cent of the total songs were recorded by male soloists, 5 per cent by male lead singers with group backing, and 17 per cent by male groups. A total of 68 per cent of the songs were performed by male artists.

Twenty-five per cent of the total sample songs were performed by female soloists, 2 per cent by female singers with group backing, and none by female groups. A total of 27 per cent of the songs were performed by female artists. Five per cent of the songs were performed by mixed groups or were instrumentals.

Differences among musical genres revealed that men in the Soul group performed the largest percentage of songs in a particular genre. Women in the Country-Western genre performed the largest percentage of songs of women in any genre.

An analysis of themes of popular songs revealed that the heterosexual relationship is the most frequent theme. Sixtynine per cent of the total sample of songs were devoted to this theme. Fifteen per cent of the songs concerned personal statements of the singer without a heterosexual theme. Five per cent of the songs concerned social values. Five per cent were novelty songs or instrumentals. Three per cent of the songs had a religious theme. Three per cent also had a nostalgic theme.

Differences among genres revealed that Country-Western songs had the highest percentage devoted to the heterosexual 
theme, with 82 per cent. Only 60 per cent of the EasyListening songs concerned this theme. Twenty per cent of the Easy-Iistening songs were personal, however, as opposed to only 10 per cent of the Country-Western songs. Songs about social values comprised 10 per cent of the Soul genre but were totally absent in the Easy-Iistening group. However, 6 per cent of the Easy-Listening songs were nostalgic, while this theme was completely absent from the Soul genre. Novelty songs comprised 8 per cent of the Soul group but were not present in the Country-Western genre. It is thought that differences in themes among genres are due in part to differences in subcultural values.

Those lyrics categorized as heterosexual in theme were subjected to further analysis to assess the type of malefemale relationship involved. Songs which extolled the qualities of a happy relationship were categorized as Love Lauded. Those which decried the problems of an unhappy relationship were categorized as Love Lamented. Those songs in which there was equal treatment of happy or unhappy elements were categorized as Balanced. The songs were further dichotomized into those performed by males and those performed by females. In both cases, the relationship between the sexes was the focal point of analysis.

Among males, 60 per cent of the total songs lauded love while 40 per cent lamented it. Among females, only 38 per cent lauded love while 62 per cent lamented it. The number 
of songs by female performers was less than the number of songs performed by males. Nevertheless, female discontent in the love relationship is articulated frequently be female singers. This is consistent with sociological studies which indicate that women report themselves as unhappy more often than happy in the marital relationship. Similar studies have concluded that men report themselves happy more often than unhappy in marriage.

Here, too, there were differences among genres. Men in Country-Western and Soul lyrics lauded love most frequently. Men in the Easy-Listening group were split, with half lauding love and the other half lamenting love.

Women in Country-Western lyrics lamented love in 67 per cent of the songs in this genre. Women in Soul lyrics also lamented love more often than they lauded it. Women in the Easy-Listening genre had similar percentages in the lauded and lamented categories. In general, in popular lyrics, men laud love and women lament it. This is consistent with sociological studies of reported marital happiness.

The songs labelled heterosexual were further assessed to determine which songs were directed to or were about women, and which songs were directed to or were about men. Those songs performed by a male and directed to a love object were presumed to be songs directed to a female. Those songs performed by females and directed to a love object were presumed to be songs directed to a male, although gender may 
not have been mentioned specifically in the lyrics. Songs which concerned couples or the theme of "love" in general were excluded from the sample. A total of ninety-four songs then remained for analysis.

of this sample of ninety-four lyrics, 71 per cent concerned women. Twenty-nine per cent of the Iyrics concerned men. Again there were differences among genres, with the Easy-Iistening songs being most often devoted to women. Country-Western songs were most concerned with men, reflecting the greater number of female performers in this genre.

Those songs labelled to or about a woman were then subjected to criteria for determining the direction of presentation. These criteria, developed by Kaplan and Goldsen (2) for use in all types of content analysis, code a symbol as being presented positively with qualification, negatively, negatively with qualification, balanced, or no direction of presentation. The last category was eliminated by confining the sample to songs already categorized as about women and men. This same procedure was also applied to songs about men.

Women were presented positively in 48 per cent of the total songs and positively with qualification in 28 per cent. In 3 per cent of the songs women were presented negatively. Women were presented negatively with qualification in 21 per cent of the songs. None belonged in the balanced category. Men were presented positively in 30 per cent of the songs about them. They were presented positively with qualification 
in 15 per cent. Men were presented negatively in 26 per cent and negatively with qualification in 30 per cent of the songs performed by women.

There were again differences among musical genres. Men in Country-Western lyrics presented women most positively. Sixty-two per cent of their lyrics were so oriented. Men in the Easy-Iistening genre portray women negatively with qualification in 29 per cent of the lyrics. This is the largest percentage of such a presentation among genres.

Women in Country-Western lyrics portray men most negatively of all genres. Thirty-nine per cent of songs about them were negative. An interesting finding is that men in Country-Western lyrics present women most positively while women in Country-Western lyrics present men most negatively. It is possible that this is related to problems of the white working-class male in a middle-class society. It may also be related to communication patterns in the working-class marital relationship.

To determine the extent to which stereotypical female and male sex roles were reinforced in popular lyrics, analyses were performed using various sex role traits. Each of the one hundred five songs previously designated as hetereosexual in theme was subjected to a sex role analysis. Six female traits and six male traits were selected for their previous association with stereotyped sex roles. For women these traits were supportive, inconsistent, submissive, dependent, 
hesitant, and beautiful. For men the traits selected were aggressive, independent, demanding, consistent, active, and confident. Each of the songs in the heterosexual group was then analyzed for each trait in turn. The songs were coded as conforming to the trait if the female portrayed in the song exhibited the specific trait. The Iyrics were coded as not conforming if the female in question exhibited an opposite trait. If the trait was not mentioned at all, the song was categorized as "trait not mentioned." The same procedure was then applied to the songs to determine conformity to the male traits previously mentioned.

In the total sample, women conformed to the supportive trait most frequently. They conformed to the submissive trait in 38 per cent of the songs. Women were also portrayed as inconsistent and beautiful in lesser numbers. However, conformity existed to all four of these traits. Women did not conform to the dependent and hesitant stereotypes.

Men conformed to five of the six stereotypical traits in the total sample of songs. The traits most frequently supported were confident and aggressive. Traits of active, consistent, and demanding were also supported, in order of frequency. The one male trait which was not supported was independence.

As in other analyses, there were differences among genres. Women in Country-Western Iyrics conformed to the supportive, submissive, and dependent traits. They did not conform to the other traits. Women in Soul lyrics conformed to the inconsistent, 
hesitant, and beautiful traits, only. Women in Easy Iistening conformed to the supportive, inconsistent, and beautiful traits but not to the other traits. These differences among genres caused lower averages of conformity to the various traits when the genres were combined.

Men in these lyrics also differed among genres, but not so much as women. Males in Soul lyrics conformed to the masculine stereotype with every trait. Men in Country-Western lyrics conformed to only three of the traits. Traits showing conformity across genres were aggressive and active. It may be that the male role is more rigidly defined across subcultures than the female role, since there is more agreement among genres of male traits than female traits. Perhaps the female role is more diverse among ethnic and cultural groups.

In general, men in Soul lyrics conformed to the black lower-class male stereotype as documented in sociological studies. Females in Soul lyrics also conformed to the black female lower-class stereotype. Men in Country-Western Iyrics did not entirely support the working-class male stereotype. Women in this genre displayed the submissive and dependent stereotypical traits. Men and women in the Easy-Iistening genre resembled the middle-class stereotypical model. Women were portrayed as supportive but independent. Men were confident, active, and aggressive, but appeared dependent on women for emotional support. 
A comparison of male and female traits paired for analysis revealed much greater adherence to the male stereotype in popular lyrics than to the female stereotype. Males were portrayed as consistent, aggressive, independent, confident, and active in lyrics over 40 per cent of the time. They appeared demanding in 37.5 per cent of the lyrics.

Females appeared as supportive in 41 per cent of the lyrics and submissive in 37.5 per cent of the songs. The other feminine stereotypical traits of inconsistent, dependent, hesitant, and beautiful appeared in about 25 per cent of the lyrics.

When the traits were compared, women appeared more supportive than men were demanding. This is a portrayal of the "help-mate" role for women. It appears to be the trait most valued in a female, even in the Soul genre. In the Soul group, women did not conform to this trait in a majority of the songs. Complaints were vocalized by males in this genre about the non-supportive nature of women. Males were depicted as aggressive in greater numbers than females appeared submissive. This figure reflects the non-submissive nature of women in Soul and Easy-Iistening lyrics. Women appear more aggressive in the love relationship in those genres. This may reflect a difference in cultural patterns of courtship and an emphasis on female self-determination. The same traits are similarly portrayed in the dependent-independent comparison. In the love 
relationship men appear more independent than women appear dependent.

The comparison of the active and beautiful traits reflects the concept of men as "doing" and women as "being." It would seem that men do conform to the active stereotype. They are portrayed as engaged in various activities in 43 per cent of the songs. Women, however, are pictured as beautiful in only 23 per cent of the lyrics. The concept of woman as an object is not present in popular lyrics in any great amount. Perhaps this stereotype has given way to a more complex personal type whose function is related to her emotional characteristics than her physical ones.

The love-sex theme in the lyrics of 1973 is more prevalent than James T. Carey found in 1966 (3). It is less prevalent than Donald Forton (6) found in 1955 or Richard Cole (5) found in the decade of the sixties. Part of this difference may be attributed to the sampling procedure. Horton used only lyric books for his sample. These books contain a large number of love songs. Carey and Cole used the Billboard sample. Carey found 67 per cent of the songs devoted to the love-sex theme in 1966. Cole found 71 per cent of the songs of the sixties concerned this theme. This study of 1973 songs based on a Billboard sample found 69 per cent of the songs devoted to the heterosexual relationship. These similar percentages indicate a steady preference on 
the part of the record-buying public for love songs. It also reflects a national emphasis on the love relationship. Charles Winick's (9) statement that women performers are more numerous in the recording field is difficult to assess, since no previous figures on women performers are available. However, since men perform 68 per cent of the songs, it is obvious that women are not as influential as men recording artists.

Popular lyrics serve two functions. They influence the thinking of listeners in various ways. Lyrics also reflect current social values. Various researchers have studied this influence and concluded that teenaged listeners to popular music engage in selective perception of song lyrics according to their ethnic background and social class position. Other researchers have documented the frequency with which teenaged girls listen to popular music. It is thought that sex role identity is formulated in part by vicariously experiencing aspects of life before one is actually faced with them. Popular songs, then, are in a position to influence the sex role identification process of adolescents, especially female adolescents, since research has shown that they listen to popular songs more often than males. As Heinz Luthe (8) stated, we do not know what the effects of repetitive record playing may be. Nevertheless, popular songs are presenting stereotypical views of women, especially to black and working-class girls. Rock lyrics 
may present a slightly less stereotyped view of the female role. Further, popular lyrics also influence males to expect stereotypical behavior from females. Stereotypical traits of the black female are reinforced in Soul lyrics to such an extent that they undoubtedly influence black girls who may be formulating a sex role identity. As such, they function to make the attaining of sex role identification more difficult than it need be. The negative portrayal of the working-class male in Country-Western lyrics is especially insidious. Males in this cultural group may experience a feeling of inferiority in song long before they encounter problems in the larger society. Women, however, are presented positively for displaying the stereotypical traits. Males are more often presented negatively by women for displaying stereotypical traits such as being demanding. Women, then, are possibly more influenced by song lyrics than are men.

Song lyrics also reflect current social values. It is possible that Soul lyrics function as a vehicle for black protest. They may, as Elliot Liebow (7) suggested, also reflect lip service to a black lower-class cultural ideal which is not taken too seriously. Country-Western lyrics, while portraying a negative male image, may also serve as a means to articulate anxieties and problems which working-class men are not able to express in any other way. They also serve as a means for white working-class females to express 
discontent with the male-female relationship. As such they serve a useful function. Unfortunately, they also serve to reinforce the submissive trait in songs about women. As Jessie Bernard (1) has stated, in male-female communication, the sexes learn who they are from what they tell each other. Further studies might be formulated to assess the sex role imagery in rock lyrics alone, and to compare these to Country-Western and Soul lyrics. This was difficult to do in the Easy-Listening group of songs, since several types of Iyrics were categorized together. Janet Chafetz' study (4) found women of little or no concern in rock lyrics. However, she found women conforming to feminine stereotypical traits in thirty-three popular songs undifferentizted as to genre. No studies have been conducted to determine how much of the sex role imagery contained in popular lyrics is actually perceived by adolescents. This would be a useful study. Albums as well as single records should be studied in all genres.

Popular lyrics both reflect and influence sex role identification to an extent that is unknown. In this respect lyrics are contributing to the perpetuation of stereotypical sex role behavior to the detriment of both males and females. 
1. Bernard, Jessie, The Sex Game, Englewood Cliffs, New Jersey, Prentice Hali, Inc., 1968.

2. Budd, Richard W., Robert Thorp, and Lewis Donohew, Content Analysis of Communications, New York, The Macmillan Company, 1967.

3. Carey, James T., "Changing Courtship Patterns in the Popular Song," American Journal of Sociology, LXXIV (May, 1969), 720-731.

4. Chafetz, Janet Saltzman, Masculine/Feminine or Human?: An Overview of the Sociology of Sex Roles, Itasca, IIlinois, F. E. Peacock Publishers, Inc., 1974.

5. Cole, Richard R., "Top Songs in the Sixties," American Behavioral Scientist, XIV (February, 1971), 389-399.

6. Horton, Donald, "The Dialogue of Courtship in Popular Songs," American Journal of Sociology, IXII (May, 1957), 569-578.

7. Liebow, Elliot, Tally's Corner: A Study of Negro Streetcorner Men, Boston, Little, Brown and Company, 1967 .

8. Luthe, Heinz Otto, "Recorded Music and the Record Industry," International Social Science Journal, $\mathrm{XX}$, No. $4\left(\frac{1}{1968)}, 656-666\right.$.

9. Winick, Charles, The New People: Desexualization in American Society, New York, Western Publishing Co., 1968. 
APPENDIX A

The Fifty Most Popular Single Records--1973

\section{Easy Listening}

Song

1. Delta Dawn

2. And I Love You So

3. Loves Me Like a Rock

4. Tie a Yellow Ribbon 'Round the old Oak Tree

5. Say, Has Anyone Seen My Sweet Gypsy Rose?

6. Sing

7. Boogie Woogie Bugle Boy

8. My Love

9. You Are the Sunshine of My Life

10. Yesterday Once More

11. Danny's Song

12. Clair

13. Daniel

14. Daisy a Day

15. Touch $\mathrm{Me}$ in the Morning

16. My Maria

17. All I Know

18. Bad, Bad Leroy Brown

19. I'm Comin' Home

20. Rocky Mountain High

21. Last Song

22. Dueling Banjos

23. Half-Breed

24. You're So Vain

25. Get Down

26. Don't Expect Me to Be Your Friend

27. Peaceful

28. Oh, Babe, What Would You Say?

29. Out of the Question

30. Behind Closed Doors

31. Separate Ways

32. Playground in My Mind

33. Right Thing to Do

34. Killing Me Softly with His Song
Artist

Helen Reddy

Perry Como

Paul Simon

Tony Orlando and Dawn

Tony Orlando and Dawn

The Carpenters

Bette Midler

Paul McCartney and Wings

Stevie Wonder

The Carpenters

Anne Murray

Gilbert 0'Sullivan

Elton John

Jed Strunk

Diana Ross

B. W. Stevenson

Art Gardunkel

Jim Croce

Johnny Mathis

John Denver

Edward Bear

Eric Weissberg

Cher

Carly Simon

Gilbert 0'Sullivan

Lobo

Helen Reddy

Hurricane Smith

Gilbert 0'Sullivan

Charlie Rich

Elvis Presley

Clint Holmes

Carly Simon

Roberta Flack 
35. Loving Arms

36. How Can I Tell Her?

37. Diamond Girl

38. Jimmy Loves Mary-Ann

39. Ashes to Ashes

40. Sweet Surrender

41. In the Midnight Hour

42. Paper Roses

43. You Iight Up My Iife

44. Clouds

45. The Morning After

46. Smoke Gets in Your Eyes

47. 2001 Theme

48. Walk on Water

49. Give Me Love (Give Me Peace on Earth)

50. Kodachrome
Dobie Gray

Lobo

Seals and Croft

Looking Glass

Fifth Dimension

Bread

Cross Country

Marie Osmond

Carole King

David Gates

Maureen McGovern

Blue Haze

Deodato

Neil Diamond

George Harrison

Paul Simon

Soul

Song

1. Let's Get It on

2. Superstition

3. Neither one of Us

(Wants to $\mathrm{Be}$ the First to Say Goodbye)

4. Me and Mrs. Jones

5. Why Can't We Live Together?

6. One of a Kind (Love Affair)

7. Love Train

8. Doing It to Death

9. Midnight Train to Georgia

10. Love Jones

11. I'm Gonna Love You Just a Iittle Bit More

12. Could It Be I'm Falling in Love?

13. Masterpiece

14. Natural High

15. Pillow Talk

16. That Lady

17. Give Your Baby a Standing Ovation

18. Keep on Truckin'

19. If You Want Me to Stay

20. The World Is a Ghetto

21. Superfly

22: Here I Am (Come and Take Me)
Artist

Marvin Gaye

Stevie Wonder

Glady Knight and the Pips Billy Paul

Timmy Thomas

Spinners

0 'Jays

Fred Wesley and J.B.'s

Gladys Knight and the Pips

Brighter Side of Darkness

Barry White

Spinners

The Temptations

Bloodstone

Sylvia

Isley Brothers

Delis

Eddie Kendricks

Sly and the Family Stone

War

Curtis Mayfield

Al Green

Chi-Lites 
24. Give Me Your Love

25. Ain't No Woman (Iike the one I Got)

26. Leaving Me

27. Trouble Man

28. Angel

29. Funky Stuff

30. Daddy Could Swear, I Declare

31. Funky Worm

32. Hurt So Good

33. Higher Ground

34. Will It Go Round in Circles

35. Nobody Knows You When You're Down and out

36. Hey Girl (I Like Your Style)

37. There's No Me Without You

38. Gypsy Man

39. Daddy's Home

40. Time To Get Down

41. You Ought to Be with Me

42. We Did It

43. I Can't stand the Rain

44. Get It Together

45. Touch $\mathrm{Me}$ in the Morning

46. I've Got So Much to Give

47. Are You Man Enough?

48. Killing Me Softly With His Song

49. Theme from Cleopatra Jones

50. Harry Hippie
Barbara Mason

Four Tops

Independents

Marvin Gaye

Aretha Franklin

Kool and the Gang

Gladys Knight and the Pips

Ohio Players

Millie Jackson

Stevie Wonder

Billy Preston

Bobby Womack

The Temptations

Manhattans

War

Jermaine Jackson

o'Jays

Al Green

SyI Johnson

Ann Peebles

Jackson Five

Diana Ross

Barry White

Four Tops

Roberta Flack

Joe Simon

Bobby Womack

\section{Country-Western}

\section{Song}

1. You've Never Been This

Far Before

2. Behind Closed Doors

3. Satin Sheets

4. Teddy Bear Song

5. Amanda

6. You're the Best Thing That Ever Happened to $\mathrm{Me}$

7. Why $\mathrm{Me}$

8. Everybody's Had the Blues

9. She Needs Someone to Hold Her

10. The Lord Knows I'm Drinking

11. What's Your Mama's Name?

12. She's Got to Be a Saint

13. Love is the Foundation

14. Kids Say the Darndest Things
Artist

Conway Twitty

Charlie Rich

Jeanne Pruett

Barbara Fairchild

Don Williams

Ray Price

Kris Kristofferson

Merle Haggard

Conway Twitty

Cal Smith

Tanya Tucker

Ray Price

Loretta Lynn

Tammy Wynette 
15. Rated $X$

16. Trip to Heaven

17. Don't Fight the Feelings of Love

18. Old Dogs, Children and Watermelon Wine

19. Come Live With Me

20. You Always Come Back (To Hurting Me)

21. Till I Get It Right

22. Slippin' Away

23. Ridin' My Thumb to Mexico

24. Keep Me in Mind

25. If Teardrops Were Pennies

26. Blood Red and Goin' Down

27. Got the All Overs for You

28. I Wonder if They Ever Think of Me

29. Superman

30. Neon Rose

31. Lord, Mr, Ford

32. Kid Stuff

33. A Shoulder to Cry on

34. Can I Sleep in Your Arms?

35. Louisiana Woman, Mississippi Man

36. The Corner of My Life

37. Do You Know What It's Like to $\mathrm{Be}$ Lonesome

38. Any 0Id Wind that Blows

39. Soul Song

40. Super Kind of Woman

41. You Were Always There

42. Yellow Ribbon

43. Top of the World

44. Red Necks, White Socks and BIue Ribbon Beer

45. Danny's Song

46. Good Things

47. Mr. Lovemaker

48. Pass My By

49. Love's the Answer

49. Jamestown Ferry

50. I Love You More and More Everyday
Loretta Lynn Freddie Hart

Charley Pride

Tom T. Hall

Roy Clark

Johnny Rodriguez

Tammy Wynette

Jean Shepard

Johnny Rodriguez

Lynn Anderson

Porter Waggoner and

Dolly Parton

Tanya Tucker

Freddie Hart and the

Heartbeats

Merle Haggard

Donna Fargo

Mel Tillis and the

Statesiders

Jerry Reed

Barbara Fairchild

Charley Pride

Jeannie Seely

Loretta Iynn and

Conway Twitty

Bill Anderson

Jerry Wallace

Johnny Cash

Joe Sampley

Freddie Hart

Donna Fargo

Johnny Carver

Lynn Anderson

Johnny Russell

Anne Murray

David Houston

Johnny Paycheck

Johnny Rodriguez

Tanya Tucker

Tanya Tucker

Sonny James 


\section{APPENDIX B}

Definition of Categories for the Analysis of Theme

Heterosexual The singer speaks of a love relationship or sexual relationship between himself and a love object or between two other people. It should be clear that male-f'emale relations are the dominant theme of the Iyrics.

Personal

The singer extols qualities of himself or herself, a friend, parent, sibling, or other relative. The most important criterion is male-female relations are not dominant as the theme.

Social Values The dominant theme here is either the environment in which one lives or personal values regarding social change, social conflict, or social values.

Religious

Specific mention is made to or about a deity, spiritual values, or another religious symbol such as the devil, etc. This should be the dominant theme of the song.

Nostalgia The singer mentions as the dominant theme of the song either his childhood or times past such as the "good old days."

Novelty

This category includes instrumentals with no Iyrics, songs with nonsensical, unintelligable, or repetitious lyrics which do not contain any of the above themes. 
Definition of Categories for Analysis of

Direction of Presentation

Category 1 Favorable presentation of the symbol

Unqualified without explicit qualification of its

Positive favorable character.

Category 2

Qualified

A basically favorable presentation,

Positive with unfavorable aspects clearly involved.

Category 3

Unqualified

Unqualified unfavorable presentation.

Negative

Category 4

Qualified

Negative

Basically unfavorable, with favorable or ameliorating aspects clearly involved.

Category 5

Balanced

Both favorable and unfavorable

Category 6 presentations clearly and equally involved.

No Direction

Presentations involving neither favorable nor unfavorable aspects. 


\section{Definition of Female Sex Role Characteristics}

1. Supportive

2. Inconsistent

3. Submissive

4. Dependent

5. Hesitant

6. Beautiful
The female is portrayed as giving courage, faith, and confidence, helping, strengthening, and comforting.

The female is not uniform in behavior. A changeable nature is exhibited.

The female is shown to be docile, yielding, and is portrayed as submitting without resisting.

The female is portrayed as being influenced, controlled or dominated by someone else. She may also be shown as relying on someone else for physical or emotional support.

The female is undecided, vacillating, doubtful, or reluctant in her behavior.

It is suggested that she approximates one's conception of an ideal. She gives the highest degree of pleasure to the senses.

\section{Definition of Male Sex Role Characteristics}

1. Aggressive

2. Demanding

3. Independent

4. Consistent

5. Active

6. Confident
He is shown as full of initiative or in an energetic pursuit of a goal.

The male asks urgently or with authority or as a right for the object.

He is portrayed as free from the influence, control, or determination by another.

He is shown holding to some principle or practice, e.g., consistent behavior.

He is shown in action, motion, or in the use of energy. Specific activities should be mentioned.

He is portrayed as self-assured or certain. 


\section{APPENDIX C}

\section{Reliability Indices}

$\begin{array}{ll}\text { Analysis } 1 & 99.3 \% \\ \text { Analysis 2 } & 94.0 \% \\ \text { Analysis 3 } & 97.3 \% \\ \text { Analysis 4 } & 98.0 \% \\ \text { Analysis 5 } & 84.0 \% \\ \text { Analysis 6 } & 75.0 \%\end{array}$




\section{BIBLIOGRAPHY}

\section{Books}

Allen, Gary, "More Subversion Than Meets the Ear," The Sounds of Social Change, edited by $R$. Serge Denisoff and Richard A. Peterson, Chicago, Rand McNally and Company, 1972 .

Bardwick, Judith and Elizabeth Douvan, "Ambivalence: The Socialization of Women," Woman in Sexist Society, edited by Vivian Gornick and Barbara K. Moran, New York, Basic Books, Inc., 1971.

Beckett, Alan and Richard Merton, "Stones/Comment," The Age of Rock: Sounds of the American Social Revolution, edited by Jonathan Eisen, New York, Vintage Books, A Division of Random House, 1969.

Belz, Carl, The Story of Rock, New York, Oxford University Press, 1972 .

Benson, Leonard, The Family Bond: Marriage, Love, and Sex in America, New York, Random House, 1971.

Berelson, Bernard, Content Analysis in Communication Research, Glencoe, Illinois, The Free Press, 1952.

Bernard, Jessie, The Sex Game, Englewood Cliffs, New Jersey, Prentice Hali, Inc., 1968.

Brenton, Myron, The American Male, New York, Coward-McCann, Inc. , 1966.

Budd, Richard W., Robert K. Thorp, and Lewis Donohew, Content Analysis of Communications, New York, The Macmillan Company, 1967 .

Carney, Thomas F., Content Analysis: A Technique for Systematic Inference from Communications, Winnipeg, Canada, University of Manitoba Press, 1972.

Chafetz, Janet Saltzman, Masculine/Feminine or Human?: An Overview of the Sociology of Sex Roles, Itasca, Illinois, F. E. Peacock Publishers, Inc., 1974. 
Coleman, James Samuel, The Adolescent Society: The Social Iife of the Teenager and Its Impact on Education, New York, The Free Press, 1961 .

Denisoff, R. Serge and Richard A. Peterson, "Changing Musical Tastes," The Sounds of Social Change, Chicago, Rand MeNally Co. , 1972 .

Culture, Music, and Society," The Sounds of Social Change, Chicago, Rand McNally Co., 1972.

Dimaggio, Paul, Richard A. Peterson, and Jack Esco, Jr., "Country Music: Ballad of the Silent Majority," The Sounds of Social Change, edited by R. Serge Denisoff and Richard A. Peterson, Chicago, Rand McNally and Co., 1972 .

Ferguson, Charles Wright, The Male Attitude, Boston, Iittle, Brown, and Co., 1966.

Gillett, Charlie, The Sound of the City, New York, Outerbridge and Dienstfrey, 1970.

Gleason, Ralph, "A Cultural Revolution," The Sounds of Social Change, edited by $R$. Serge Denisoff and Richard A. Peterson, Chicago, Rand McNally and Co., 1972.

Goldstein, Richard, editor, The Poetry of Rock, New York, Bantam Books, 1969.

Greenburg, Bradley S, and Brenda Dervin, Use of the Mass Media by the Urban Poor, New York, Praegar Publisher, 1970 .

Hayakawa, S. I., "Popular Songs vs. the Facts of Iife," Mass Culture: The Popular Arts in America, edited by Bernard Rosenberg and David Manning White, Glencoe, Illinois, The Free Press, 1957.

Hodenfield, Chris, "The 60's Recollected: An Incisive Report," Mass Media: Forces in our Society, edited by Francis and Ludmila Voelker, New York, Farcourt Brace Jovanovich, 1972 .

Holsti, Ole R., Content Analysis for the Social Sciences and Humanities, Reading, Massachusetts, Addison-Wesley Publishing Co., 1969. 
Horowitz, Irving Louis, "Bubblegum Anyone?" Mass Culture Revisited, edited by Bernard Rosenberg and David Manning White, New York, Van Nostrand Reinhold Co., 1971 .

Horton, Paul B. and Chester S. Hunt, Sociology, New York, McGraw Hill Book Company, 1972.

Hunt, Morton, "The Age of Love," America as a Mass Society, edited by Phillip olson, Glencoe, Illinois, The Free Press, 1963.

Jones, LeRoi, Black Music, New York, W. Morrow, 1967.

Keil, Charles, Urban Blues, Chicago, The University of Chicago Press, $196 \overline{9}$.

Komarovsky, Mirra, Blue-Collar Marriage, New York, Vintage Books, A Division of Random House, 1967.

Komisar, Lucy, "The Image of Woman in Advertising," Woman in Sexist Society, edited by Vivian Gornick and Barbara $\bar{K}$. Moran, New York, Basic Books, Inc., 1971.

Larkin, Rochelle, "The Soul Message," The Sounds of Social Change, edited by R. Serge Denisoff and Richard A. Peterson, Chicago, Rand McNally and Co., 1972.

Liebow, Elliot, Tally's Corner: A Study of Negro Streetcorner Men, Boston, Iittele, Brown and Company, 1967 .

Lund, Jens, "Fundamentalism, Racism, and Political Reaction in Country Music," The Sounds of Social Change, edited by R. Serge Denisoff and Richard A. Peterson, Chicago, Rand McNally and Co., 1972.

McLuhan, Marshal1, Understanding Media: The Extensions of Man, New York, New American Library, Inc., 1964.

Malone, Bill, Country Music U.S.A., Austin, University of Texas Press, 1968.

Marcus, Greil, "Who Put the Bomp in the Bomp De-Bomp De-Bomp?" The Popular Arts in America, edited by William M. Hammel, New York, Harcourt Brace Javanovich, Inc., 1972.

Martin, Wendy, "Seduced and Abandoned in the New World: The Image of Woman in American Fiction, "Woman in Sexist Society, edited by Vivian Gornick and Barbara K. Moran, $\overline{N e w}$ York, Basic Books, Inc., 1971. 
Meade, Marion, "The Degradation of Women," Sounds of Social Change, edited by R. Serge Denisoff and Richard A. Peterson, Chicago, Rand McNally and Co., 1972.

Mooney, H. F., "Popular Music Since the 1920's: The Significance of Shifting Taste," The Popular Arts in America, edited by William M. HammeI, New York, Harcourt Brace Jovanovich, Inc., 1972.

Peatman, J., "Radio and Popular Music," Radio Research: 1942-43, edited by Paul Lazarsfeld and $\bar{F}$. Stanton, New York, Duell, Sloan and Pearce, 1944.

Peterson, Richard A. and David G. Berger, "Three Eras in the Manufacture of Popular Music Lyrics," The Sounds of Social Change, edited by $R$. Serge Denisoff and Richard A. Peterson, Chicago, Rand McNally and Co., 1972 .

Riesman, David, "Listening to Popular Music," Mass Culture: The Popular Arts in America, edited by Bernard Rosenberg and David Manning White, Glencoe, Illinois, The Free Press, 1957.

Robinson, John P., and Paul M. Hirsch, "Teenage Response to Rock'n'Roll," The Sounds of Social Change, edited by R. Serge Denisoff and Richard A. Peterson, Chicago, Rand McNally and Company, 1972.

Sellitz, Claire, and Marie Jahoda, Morton Deutsch and Stuart W. Cook, Research Methods in Social Relations, New York, Holt, Rinehart and Winston, 1959.

Shaw, Arnold, "Soul Is," The Popular Arts in America, edited by William M. Hammel, New York, Harcourt Brace Jovanovich, Inc., 1972.

U'Ren, Marjorie B., "The Image of Women in Textbooks," Women in Sexist Society, edited by Vivian Gornick and Barbara K. Moran, New York, Basic Books, Inc., 1971.

Winick, Charles, The New People: Desexualization in American Society, New York, Western Publishing Company, 1968. 
Articles

Bolton, Charles D., "Mate Selection as the Development of a Relationship," Marriage and Family Living, XXIII (August, 1961), 234-240.

Braudy, Susan, "The Queen of Country Music: 'Stand By Your Man, " MS, I, No. 9 (March, 1973), 27-31.

Carey, James T., "Changing Courtship Patterns in the Popular Song," American Journal of Sociology, IXXIV (May, 1969), $720-731$.

, "The Ideology of Autonomy in Popular Lyrics:

A Content Analysis," Psychiatry, XXXII (May, 1969), $150-164$.

Cole, Richard R., "Top Songs in the Sixties," American Behavioral Scientist, XIV (January-February, 1971), 389-399.

Hirsch, Paul M., "Sociological Approaches to the Pop Music Phenomenon," The American Behavioral Scientist, XIV (January-February, 1971), 371-388.

Horton, Donald, "The Dialogue of Courtship in Popular Songs," American Journal of Sociology, LXII (May, 1957), 569-578.

Klein, Viola, "The Stereotype of Femininity," Journal of Social Issues, VI, No. 3 (1950), 3-9.

Kracaur, Siegfried, "The Challenge of Qualitative Content Analysis," Public opinion Quarterly, XVI (Winter, 1952-53), $631-642$.

Luthe, Heinz 0tto, "Recorded Music and the Record Industry," International Social Science Journal, XX, No. 4 (1968), $656-666$.

Newsweek, June 18, 1973, pp. 64-72.

Scodel, Alvin, "Changes in Song Lyrics and Some Speculations on National Character," Merrill-Palmer Quarterly, VII (January, 1961), 39-47.

Time, "The Distant Message of the Transistor," November 24, 1967, pp. 46-48.

Time, "Lord, They've Done It Al1," May 6, 1974, pp. 51-55. 
Encyclopedia

The American Almanac for 1974, "Commercial Broadcast Stations on the Air--States and Other Areas: January 1, 1972," New York, Grosset and Dunlap. Inc., 1973.

Unpublished Manuscripts

Wardell, Robert E., "Priorities in Mate Selection: What People Look For in an Ideal Mate, " unpublished paper read before the Southwestern Social Science Association, Dallas, Texas, March 28, 1974. 